\title{
Avaliação de estratégias para a mitigação dos impactos ambientais de revestimentos argamassados no Brasil
}

\author{
Evaluation of strategies for the environmental impacts' \\ mitigation of mortar coatings in Brazil
}

\begin{abstract}
Lucas Rosse Caldas
Michele Tereza Marques Carvalho Romildo Dias Toledo Filho

\section{Resumo}

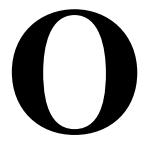

presente estudo teve como objetivo avaliar os potenciais impactos ambientais de diferentes traços de argamassas (chapisco e camada única) e combinações normalmente utilizadas nas edificações brasileiras. Foram avaliados dois tipos de processo executivo para o chapisco (convencional e rolado) e para a camada única (convencional e projetado). Foi utilizada a metodologia de Avaliação do Ciclo de Vida (ACV) com o escopo fabricação das matérias-primas, transporte, execução, destinação final das perdas e carbonatação do revestimento. O processo executivo, principalmente em termos de consumo de material, mostrou ser o fator mais importante para a mitigação dos impactos ambientais dos revestimentos argamassados. Foi verificado que é possível reduzir de $15 \%$ a $64 \%$ de impactos ambientais do revestimento somente pela escolha da técnica de execução. O estudo tem como principal contribuição a proposição de diretrizes ambientais, com base em uma análise quantitativa, para a especificação e a execução de revestimentos argamassados no Brasil.

Palavras-chave: ACV. Chapisco. Argamassa projetada.

${ }^{1}$ Lucas Rosse Caldas ${ }^{1}$ Universidade Federal do Rio de Janeiro Rio de Janeiro - RJ - Brasil

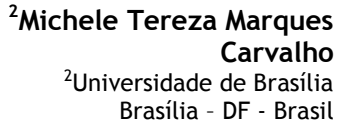

${ }^{3}$ Romildo Dias Toledo Filho ${ }^{3}$ Universidade Federal do Rio de Janeiro Rio de Janeiro - RJ - Brasil

Recebido em 04/09/19 Aceito em 16/03/20

\section{Abstract}

This study aimed to evaluate the environmental impacts of different mortar mixtures (roughcast and rendering) and their combinations, commonly used in the Brazilian buildings. Two types of construction process were evaluated for the roughcast (conventional and rolled processes) and for the rendering (conventional and projected processes). We used the Life Cycle Assessment (LCA) methodology considering the scope with the following stages: raw materials manufacturing, transport to the site, construction, end-of-life of the wastes generated during the process and the coating carbonation. We verified that it is feasible to reduce from $15 \%$ to $64 \%$ of environmental impacts of the coating only by choosing the construction technique. The main contribution of this study is the proposition of environmental guidelines, based on a quantitative analysis, for the specification and construction of mortar coatings in Brazil.

Keywords: LCA. Roughcast. Projected mortar.
\end{abstract}




\section{Introdução}

A construção civil é apontada como um dos principais setores de consumo de recursos naturais e geração de impactos ambientais. Espera-se que países em desenvolvimento, como os da América Latina, Ásia e Âfrica, sejam os de maior crescimento populacional e por demanda de habitações nos próximos anos (UNITED..., 2017). No Brasil estima-se que exista um déficit habitacional de pelo menos 6 milhões de habitações conforme dados da Fundação João Pinheiro (2016) e que esse número tende a crescer conforme previsões recentes do Governo (BRASIL, 2018).

Entre os elementos de uma edificação, o revestimento é um dos mais importantes, tendo em vista sua função de proteção, durabilidade, desempenho higrotérmico e acústico, entre outros, além do fato de ser um grande consumidor de matérias-primas.

No Brasil o revestimento mais utilizado é o argamassado, realizado com camadas de argamassa, sendo as mais comuns o chapisco e a camada única, como aponta Carasek (2010). As argamassas utilizadas nessas camadas têm diferentes composições, sendo a argamassa de chapisco convencional normalmente composta de cimento, areia e água, enquanto na camada única (também chamada de massa única ou de emboço paulista) utiliza-se argamassa mista, em que, além de cimento, areia e água, se emprega a cal hidratada (YAZIGI, 2016).

Por outro lado, desde meados da década de 1980, o revestimento argamassado vem sendo melhorado. As melhorias vão desde transformações na formulação das argamassas, por exemplo, utilizando aditivos químicos, para a produção de argamassas industrializadas, atém mudanças no processo de execução, com sua mecanização, como por exemplo a difusão da argamassa projetada (GAMA JÚNIOR, 2013).

Sabe-se que para a produção e execução dos revestimentos são gerados impactos ambientais durante as etapas de extração e produção das matérias-primas, transporte e processamento. Sendo assim, os revestimentos devem merecer atenção especial tendo em vista que um dos insumos utilizados em sua produção é o cimento Portland. Ele é o material industrializado produzido em maior quantidade (em massa) no planeta, sendo apontado como responsável por aproximadamente $10 \%$ das emissões antrópicas globais de $\mathrm{CO}_{2}$ e por $6 \%$ das emissões antropogênicas de gases de efeito estufa (GEE). Portanto, tem grande influência nas questões das mudanças climáticas. No Brasil, cerca de $40 \%$ do consumo de cimento é direcionado para a produção de argamassas (UNITED... et al., 2018). Nessa ótica, diferentes tipos de argamassas e processos de execução terão diferentes impactos ambientais, que precisam ser mensurados e avaliados para uma produção mais limpa e sustentável.

A metodologia de Avaliação do Ciclo de Vida (ACV) tem despertado interesse nos últimos anos, inclusive no setor da construção brasileira, por conseguir quantificar e avaliar esses potenciais impactos ambientais ao longo do ciclo de vida dos materiais. Embora a ACV e Declarações Ambientais de Produto (DAP) já estejam difundidas no setor da construção civil em países europeus (GELOWITZ; MCARTHUR, 2017), o Brasil ainda se encontra em um estágio embrionário. Alguns produtos como cimento e materiais cimentícios como concreto e argamassa colante já possuem suas DAP (INTERNATIONAL..., 2018). No entanto, as argamassas utilizadas como revestimentos, que têm seu uso bastante frequente na construção civil brasileira, possuem poucos dados de seus impactosambientais - apenas os de alguns estudos como Albuquerque, Lira e Sposto (2018) e Caldas e Toledo Filho (2018).

$\mathrm{Na}$ literatura científica os estudos de ACV aplicados a materiais e sistemas construtivos está cada vez mais em evidência, como salientam Anand e Amor (2017). No entanto, em muitos deles são utilizados bancos de dados internacionais, como o suíço Ecoinvent, que até possui argamassas, mas com composição bastante diferente da utilizada no Brasil, como foi verificado por Caldas e Toledo Filho (2019). Nesse sentido, faz-se necessário urgentemente um estudo que apresente os impactos ambientais desses materiais de forma alinhada, em termos metodológicos, com o que vem sendo desenvolvido no contexto internacional. Tendo em vista que são materiais cimentícios básicos e frequentemente empregados na construção civil brasileira, a ACV deles tem uma grande justificativa, que servirá, posteriormente, como um importante documento para consulta de pesquisadores e profissionais que trabalhem com ACV aplicada ao setor da construção civil brasileira.

O presente trabalho teve os seguintes objetivos:

(a) avaliação dos potenciais impactos ambientais de diferentes traços de argamassas utilizadas no Brasil (chapisco e camada única); 
(b) avaliação dos potenciais impactos ambientais de diferentes combinações de revestimentos argamassados e tipos de processos executivos utilizados no Brasil; e

(c) proposição de diretrizes ambientais para a redução dos impactos dos revestimentos argamassados.

O trabalho traz como principal contribuição uma avaliação ambiental que considera sete categorias de impacto ambiental, e não apenas questões relacionadas às mudanças climáticas de diferentes tipos de revestimentos argamassados. Somado a isso, levam-se em conta três aspectos em conjunto (traços de argamassa, combinação entre eles e processos de execução), enquanto a maioria dos estudos presentes na literatura tem o foco em apenas um dos aspectos. A partir dessa avaliação mais sistêmica, é possível traçar diretrizes que possam auxiliar projetistas, construtores e fabricantes de materiais.

\section{Argamassas e avaliação do ciclo de vida}

As pesquisas sobre ACV de edificações e seus produtos têm aumentado nos últimos anos tanto internacionalmente quando nacionalmente (ANAND; AMOR, 2017), muitas delas com interesse em comparar diferentes materiais cimentícios ou insumos utilizados em sua produção, como cimentos de baixo impacto (PASSUELO et al., 2014), concretos alternativos, como o geopolímero (BORGES et al., 2014), agregados (SANTORO; KRIPKA, 2016) e estruturas de quebra-mar com concretos ativados por álcalis (SILVA; GOMES; SAADE, 2018).

Caldas, Lira e Sposto (2017) verificaram que o revestimento argamassado é responsável por emissões de $\mathrm{CO}_{2}$-eq consideráveis do sistema de alvenaria com blocos cerâmicos, enquanto Caldas e Toledo Filho (2018) mostraram que o revestimento também apresenta participação expressiva para sistema de alvenaria de blocos de concreto. Souza et al. (2016) também corroboram com a importante contribuição da argamassa nos impactos ambientais de sistemas construtivos de alvenaria estrutural. Medeiros, Durante e Callejas (2018) verificaram que o revestimento de argamassa é o que mais contribui para os impactos da vedação em termos de depleção fóssil e ressaltam que no banco de dados do Ecoinvent não existem dados para o contexto brasileiro. Evangelista et al. (2018) mostraram que o revestimento de argamassa também é impactante para a toxidade humana. Esses resultados mostram a importância de se pensar na redução dos impactos ambientais do sistema de revestimento argamassado e na necessidade de avaliar diferentes formas de reduzi-los. Por outro lado, em todos esses estudos apenas uma configuração de revestimento argamassado é considerada, e sabe-se que no Brasil existem diferentes traços e formas de especificação, havendo, portanto, uma lacuna.

Gama Júnior (2013) comparou as emissões de $\mathrm{CO}_{2}$ entre argamassas rodadas em obra e industrializadas com base em dados de duas obras na cidade de Goiânia, GO. Caldas et al. (2016) avaliaram como o Sistema Nacional de Pesquisa de Custos e Índices da Construção (Sinapi) pode auxiliar no estudo de argamassas de chapisco e mostraram que o chapisco rolado é menos impactante que o chapisco convencional. Cirilo e Melo (2018) comparou impactos ambientais entre argamassas rodadas em obra e industrializadas, e mostrou que as últimas são menos impactantes. Albuquerque, Lira e Sposto (2018) compararam argamassas convencionais e projetadas e verificaram que a técnica de projeção consegue reduzir até $50 \%$ das emissões de $\mathrm{CO}_{2}$-eq do revestimento. Caldas e Toledo Filho (2018) avaliaram diferentes materiais cimentícios, inclusive alguns traços de argamassas utilizadas nos revestimentos. Esses estudos vão mais além, já que todos têm como foco argamassas ou revestimentos. No entanto, não avaliaram como diferentes combinações, na forma de um sistema construtivo, podem influenciar em termos de impacto ambiental. Esses autores também mostraram que as argamassas presentes no banco de dados do Ecoinvent v3.3 apresentam impactos ambientais bastante diferentes das utilizadas no país para camada única.

Alguns estudos têm olhado para a redução dos impactos ambientais pela incorporação de resíduos de outros processos. De Paula et al. (2018) verificaram que a substituição de cimento por resíduos cerâmicos pode melhorar o desempenho ambiental da argamassa, além de trazer ganhos de desempenho mecânico e durabilidade. Teixeira et al. (2019) avaliaram os benefícios ambientais e de desempenho mecânico com a incorporação de cinza volante de resíduos de biomassa em Portugal. Nessas pesquisas é possível notar que normalmente o cimento Portland é substituído pelos resíduos, já que é um dos insumos mais impactantes, principalmente em termos das mudanças climáticas, para a produção de argamassas. Alguns autores, como Caldas et al. (2019), verificaram que argamassas de terra são menos impactantes que argamassas à base de cimento Portland, no entanto os últimos autores também verificaram que vidas úteis menores podem comprometer a vantagem ambiental de revestimentos à base de terra.

Internacionalmente, grande parte dos estudos de ACV aplicada às argamassas está voltada para a avaliação de argamassas inovadoras, muitas delas com o uso de resíduos, de diversas origens, como cortiça (BRAS; 
GOMES, 2015), gesso (PEDREÑO-ROJAS et al., 2019) e pozolanas como cinzas volantes e sílica ativa (PINEDA; GARCIA-MARTÍNEZ; CASTIZO-MORALES, 2017). Todos esses estudos verificaram que o emprego de resíduos trouxe benefícios ambientais. A argamassa de cortiça ainda trouxe melhorias em termos de eficiência energética para a operação da edificação escolar. Garrido, Silvestre e Flores-Colen (2017) corroboram com esses resultados mostrando que uma argamassa térmica de aerogel também traz vantagens econômicas e energéticas para a reabilitação de edificações em Portugal. Pedreño-Rojas et al. (2019) verificaram que é possível produzir argamassas de gesso com boas propriedades com uso de $100 \%$ de resíduos de chapas de gesso (sem necessidade de calcinação) com baixos impactos ambientais quando comparado com argamassas que utilizam resíduos de gesso que precisam ser calcinados. Entre as argamassas avaliadas existe especial interesse naquelas compostas de terra e terra e cal, como pode ser visto em Meliá et al. (2014). Quando comparada às argamassas de cimento, a de terra apresenta vantagens ambientais por ser um material natural e ter pequeno teor de ligantes químicos, como cal ou cimento.

Em todos esses estudos o foco está no desenvolvimento de argamassas e/ou revestimentos alternativos com o objetivo de buscar soluções mais ambientalmente amigáveis que as argamassas de cimento e mistas convencionalmente utilizadas nas edificações. Dessa forma, eles trazem uma contribuição mais acadêmica/científica, e menos aplicada à prática de mercado.

Outras pesquisas têm tido como foco a avaliação de argamassas utilizadas para restauro, em edificações históricas, principalmente para a realidade de Portugal, como Brás e Faria (2017), e da Espanha, como Pineda, Garcia-Martínez e Castizo-Morales (2017). O primeiro estudo mostrou que a redução da vida útil das argamassas aumenta as ações de manutenção necessárias principalmente pela falta de aderência ao substrato ou pelo fenômeno de lixiviação que ocorre na argamassa. Foi verificado que algumas argamassas podem ter um impacto de produção maior no início do ciclo de vida, como as argamassas à base de cimento, no entanto resultam em menor impacto global na vida útil do edifício, devido à menor frequência de manutenções e reposições. No segundo estudo foram relacionadas análise estrutural, avaliação de riscos de incompatibilidade e ACV de diferentes tipos de argamassas utilizadas no restauro de uma edificação. Quando essa relação é realizada e os resultados são normalizados, as argamassas com pozolanas se mostram as mais eficientes. Esses dois estudos trazem como avanço científico a inclusão de outras etapas do ciclo de vida, sendo aquelas relacionadas com a vida útil do revestimento, como a manutenção, que se mostra impactante dependendo da frequência com que ela ocorre. Entretanto, para isso foram utilizados dados obtidos em pesquisas experimentais, como propriedades mecânicas e envelhecimento natural e acelerado.

Do ponto de vista do mercado brasileiro, a empresa Votorantim Cimentos (INTERNATIONAL..., 2017) já publicou DAP de diferentes materiais cimentícios utilizados no Brasil, entre eles os diferentes tipos de cimento Portland (CPV-ARI, CPII-E40 e CPIII-E40 RS), concreto e argamassa colante. No entanto, ainda não tem informações relacionadas às argamassas de revestimento comumente utilizadas no país, mesmo argamassas industrializadas ou estabilizadas. Por outro lado, esses EPD podem ser utilizados como dados de entrada para a avaliação ambiental das argamassas utilizadas no Brasil, tendo em vista que diferem os tipos de cimento.

Com base na literatura pesquisada percebe-se que não existe um estudo que reúna a produção de diferentes argamassas brasileiras desde material até a composição de camadas para a produção de um revestimento, na forma de um sistema construtivo, como é recomendado pela NBR 15575 (ABNT, 2013). Nos casos brasileiros avaliados, verificou-se que normalmente é adotado somente um tipo de argamassa, e em muitos casos o traço não é sequer citado, já que o foco está na comparação de diferentes sistemas construtivos ou em toda a edificação, e não na argamassa. Além do mais, muitos dos estudos não estão alinhados à diretiva europeia para a realização da ACV de produtos da construção civil, a EN 15804 (EUROPEAN..., 2012), principalmente em termos do método de Avaliação do Impacto do Ciclo de Vida (AICV) recomendado por essa norma.

No contexto internacional, a maioria dos estudos tem se concentrado na avaliação de argamassas alternativas, e muitos deles com interesse em argamassas para melhorar questões de eficiência energética ou restauro de edificações obsoletas e/ou históricas, que é um contexto diferente de muitas das cidades brasileiras.

Nessa ótica, o presente estudo avança na fronteira do conhecimento científico, especialmente para o setor de revestimentos argamassados, por avaliar diferentes traços, de chapisco e camada única, combinação entre eles e diferentes processos de execução. Essa avaliação possibilitará uma leitura mais sistêmica e ao mesmo tempo mais realística do contexto brasileiro para a diminuição dos impactos ambientais desse setor. 


\section{Método \\ Descrição das argamassas avaliadas}

Para a composição das argamassas de chapisco e camada única foram utilizados os Cadernos Técnicos de Composições para Argamassas e Grautes (SISTEMA..., 2017), que possuem diferentes composições de argamassa, sendo consideradas as argamassas apresentadas na Tabela 1.

\section{Avaliação do Ciclo de Vida (ACV)}

De acordo com a NBR ISO 14040 (ABNT, 2009), a ACV é dividida em quatro etapas principais:

(a) definição do objetivo e escopo;

(b) inventário do ciclo de vida;

(c) avaliação do impacto do ciclo de vida; e

(d) interpretação.

As três primeiras etapas são apresentadas a seguir, e a última na seção Resultados e Discussão.

\section{Definição do objetivo, escopo e unidade funcional}

O objetivo desta ACV é comparar os potenciais impactos ambientais de diferentes combinações de revestimentos de argamassa, normalmente empregados no Brasil, considerando as camadas de chapisco (com $5 \mathrm{~mm}$ de espessura) e camada única ( $25 \mathrm{~mm}$ de espessura). Foram adotadas as mesmas argamassas e as mesmas espessuras nas partes interna e externa. A unidade funcional utilizada foi $1 \mathrm{~m}^{2}$ de vedação vertical com vida útil de projeto (VUP) de 40 anos, de acordo com a NBR 15575 (ABNT, 2013), assumindo que é uma vedação vertical externa. Como o foco do trabalho está no revestimento argamassado, foi considerado somente ele (interno e externo) presente na vedação. Dessa forma, o substrato e o acabamento final da vedação não foram incluídos, de forma similar ao estudo de Albuquerque, Lira e Sposto (2018).

Embora as argamassas avaliadas apresentem formulações diversas e provavelmente desempenhos diferentes (em termos de resistência mecânica, porosidade, etc.), quando se pensa no sistema global da vedação vertical, em que o sistema de revestimento argamassado normalmente é sobreposto por uma camada de pintura ou revestimento cerâmico (para a realidade do Brasil), é de se esperar que o sistema global em si tenha desempenho similar, assumindo que a execução foi realizada com qualidade e que há compatibilidade entre as diferentes camadas da vedação (substrato, revestimento argamassado e acabamento final).

Somado a isso, verificou-se a falta de trabalhos experimentais que possam embasar o real desempenho em uso das diferentes combinações de argamassa, sem contar a diversidade climática que existe no país. Dessa forma, para que o estudo seja viável de ser realizado, é possível afirmar que os revestimentos argamassados, embora possuam formulações diferentes, podem ser considerados com desempenho e função similar (assumindo as premissas já descritas anteriormente), já que possuem a mesma espessura e que uma parte importante do desempenho da vedação vertical está relacionada à compatibilidade com o substrato e a camada final de acabamento. Nessa ótica, assume-se que todos os revestimentos possuem a equivalência funcional considerando que eles irão revestir um substrato com mesma espessura final. Portanto, existe essa limitação, mas que pode ser superada no futuro, quando mais dados experimentais estiverem disponíveis.

Foram consideradas as seguintes etapas no escopo do estudo:

(a) produção das matérias-primas da argamassa (cimento, cal hidratada, areia, etc.);

(b) transporte das matérias-primas; mistura da argamassa;

(c) transporte e destinação final das perdas durante a execução; e

(d) carbonatação (conforme mostra a Figura 1), sendo incluídas também as etapas de reposição e fim de vida do revestimento.

Foi adotada a vida útil dos revestimentos (interno e externo) de 20 anos de acordo com a NBR 15575 (ABNT, 2013), sendo nesse caso todas as camadas do revestimento argamassado trocadas por camadas novas e enviadas ao aterro de resíduos inertes. Considerou-se que as novas argamassas utilizadas no revestimento que seria resposto possuem as mesmas etapas apresentadas na Figura 1. Considerando a VUP de 40 anos da vedação vertical, foi contabilizada somente uma reposição do revestimento. 
Tabela 1 - Traços das argamassas avaliadas e composição por metro cúbico

\begin{tabular}{c|c|c|c|c}
\hline Traço em volume & $\begin{array}{c}\text { Cimento } \\
\left(\mathbf{k g} / \mathbf{m}^{\mathbf{3}}\right)\end{array}$ & $\begin{array}{c}\text { Cal hidratada } \\
\left(\mathbf{k g} / \mathbf{m}^{\mathbf{3}}\right)\end{array}$ & $\begin{array}{c}\text { Areia } \mathbf{1} \\
\left(\mathbf{k g} / \mathbf{m}^{\mathbf{3}}\right)\end{array}$ & $\begin{array}{c}\text { Adesivo SBR } \\
\left(\mathbf{k g} / \mathbf{m}^{\mathbf{3}}\right)\end{array}$ \\
\hline Chapisco 1:3 - convencional & 405,8 & - & $1.696,2$ & - \\
Chapisco 1:4 - convencional & 325,6 & - & $1.808,3$ & - \\
Chapisco 1:5 - convencional & 273,5 & - & $1.904,2$ & - \\
Chapisco 1:3 - rolado & 314,3 & - & $1.312,2$ & 188,6 \\
Chapisco 1:4 - rolado & 250,9 & - & $1.392,3$ & 186,8 \\
Chapisco 1:5 - rolado & 210,3 & - & $1.456,1$ & 186,9 \\
Camada única 1:1:6 & 245,4 & 128,0 & $2.048,3$ & - \\
Camada única 1:1,5:7,5 & 195,3 & 152,8 & $2.032,2$ & - \\
Camada única 1:2:8 & 180,7 & 188,6 & $2.016,1$ & - \\
Camada única 1:2:9 & 169,8 & 177,1 & $2.128,4$ & - \\
Camada única 1:3:12 & 126,9 & 198,7 & $2.112,5$ & - \\
\hline
\end{tabular}

Nota: ${ }^{1}$ foi considerada massa unitária de $1.600 \mathrm{~kg} / \mathrm{m}^{3} ;$ e ${ }^{2}$ foi considerada massa unitária de $1.000 \mathrm{~kg} / \mathrm{m}^{3}$.

Figura 1 - Escopo e etapas avaliadas neste estudo para $1 \mathrm{~m}^{2}$ de vedação vertical

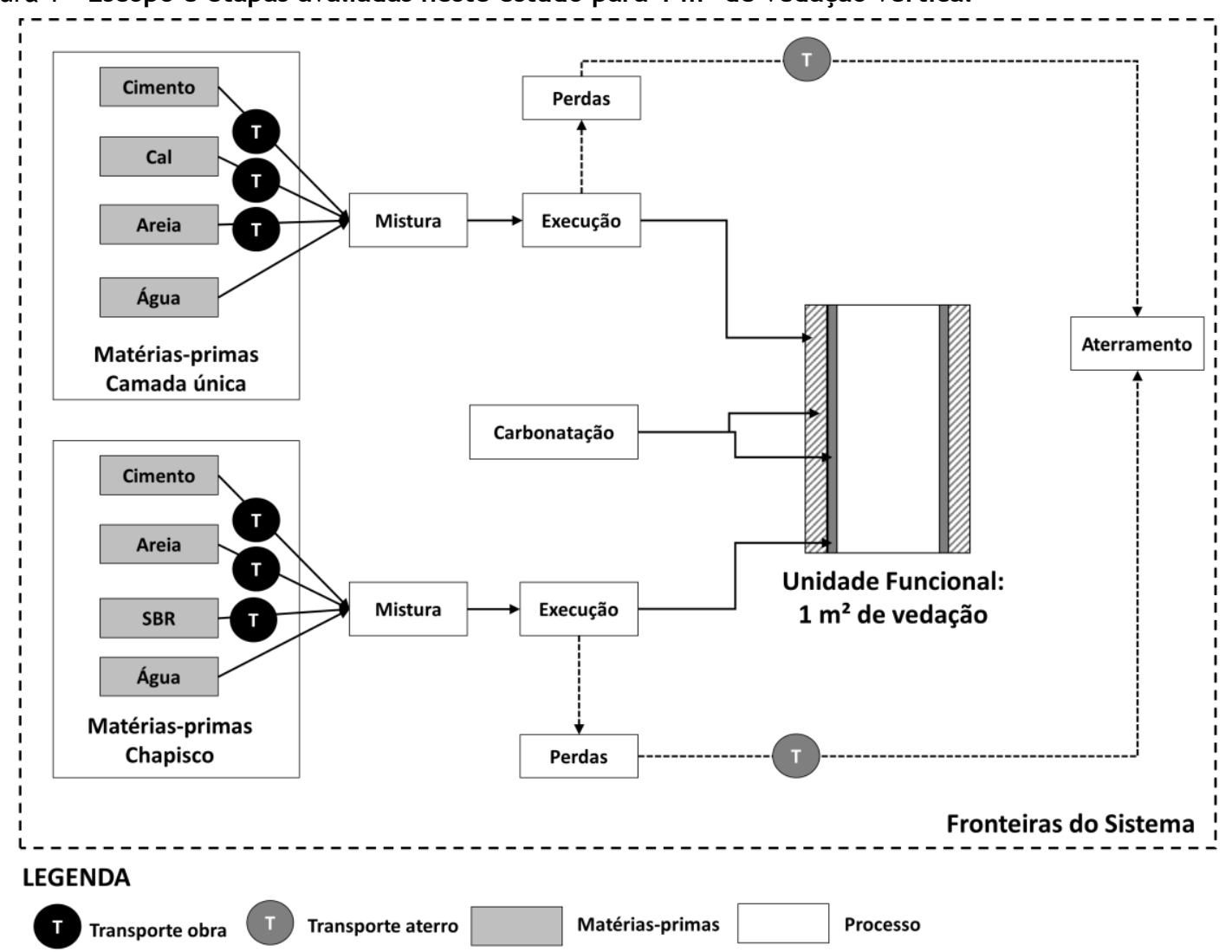

\section{Inventário do ciclo de vida}

Para a areia e cal hidratada foram considerados dados do Ecoinvent v3.3. Para o cimento Portland foram utilizados os dados da DAP da Votorantim Cimentos (INTERNATIONAL..., 2017), que avaliou diferentes cimentos produzidos na empresa (CPV-ARI, CPII-E40 e CPIII-RS), considerando o contexto brasileiro. Foi escolhido aquele com substituição de clínquer por escória granulada de alto forno de $6 \%$ a $34 \%$, que corresponde ao cimento CPII-E, um tipo de cimento comumente utilizado para a produção de argamassas no Brasil. A quantificação da água utilizada nas misturas foi retirada do escopo tendo em vista que apresentou impactos desprezíveis (menores que $1 \%$ ) para as categorias de impacto avaliadas. 
Para o aditivo químico utilizado no chapisco rolado foi considerada sua base química borracha de butadieno estireno (SBR), sendo adotado um processo disponível no Ecoinvent v3.3.

Para o transporte da areia adotaram-se três distâncias: $50 \mathrm{~km}, 100 \mathrm{~km}$ e $200 \mathrm{~km}$. Para o cimento e cal hidratada, $100 \mathrm{~km}, 200 \mathrm{~km}$ e $400 \mathrm{~km}$. Para o adesivo SBR, $300 \mathrm{~km}, 600 \mathrm{~km}$ e $1.200 \mathrm{~km}$, assumindo que se trata de um material de produção local. Para o transporte dos resíduos gerados durante a execução do revestimento foram adotados $20 \mathrm{~km}, 40 \mathrm{~km}$ e $60 \mathrm{~km}$. A avaliação da variação das distâncias de transporte em um estudo de ACV é importante, como é visto no estudo de Escamilla et al. (2018). Foram adotadas três distâncias como uma forma de ter uma distribuição triangular, de forma similar ao trabalho de Pittau et al. (2018), sendo avaliados um cenário otimista (menores distâncias), um intermediário e um pessimista (maiores distâncias). A diferenciação entre os materiais se deu principalmente entre materiais de produção mais intensiva (cimento e cal), que tendem a ter distâncias maiores. Silva (2015) recomenda distâncias máximas de $500 \mathrm{~km}$ para o cimento Portland e a areia. No caso da britada, um material de acesso mais fácil (em grande parte das cidades), foram consideradas distâncias menores, próximas ao estudo de Martins et al. (2018).Para o transporte dos resíduos ao aterro de resíduos inertes foram adotadas distâncias compatíveis com a escala urbana, os mesmos valores adotados por De Paula et al. (2018). Para a mistura da argamassa foi considerada betoneira com capacidade nominal de $400 \mathrm{~L}$ e motor elétrico trifásico de potência de $2 \mathrm{CV}$, de acordo com dados do Sinapi (SISTEMA..., 2017). Para o equipamento foi considerado somente o consumo de energia elétrica. Na Tabela 2 são apresentadas as atividades e datasets considerados.

Para a etapa de execução do revestimento de argamassa foram avaliadas quatro formas, o método convencional e o rolado para chapisco, e o convencional e o projetado para camada única, conforme dados de Caldas et al. (2016) e Albuquerque, Lira e Sposto (2018) respectivamente (Tabela 3). Foram considerados os traços avaliados anteriormente. Essa avaliação tem o objetivo de saber como o processo executivo pode influenciar nos impactos ambientais dos revestimentos argamassados. É importante ressaltar uma limitação dessa escolha, pois os traços avaliados para camada única podem não ser adequados para a aplicação em um dos processos, principalmente em relação a questões de reologia da argamassa. No entanto, é válido para o objetivo deste estudo, que pretende indicar qual item é mais importante para a mitigação dos impactos ambientais de revestimentos argamassados.

Tabela 2 - Insumos e atividades com seus respectivos datasets e fontes, considerados no inventário do ciclo de vida

\begin{tabular}{l|l}
\hline \multicolumn{1}{c|}{ Insumos } & \multicolumn{1}{c}{ Datasets e fontes } \\
\hline Cimento Portland CPII-E32 & CPII-E-40, DAP Votorantim Cimentos \\
\hline Areia & Sand $\{G L O\}$, Ecoinvent v3.3 \\
\hline Cal hidratada & Lime, hydrated, packed $\{G L O\}$, Ecoinvent v3.3 \\
\hline Resina estireno-butadieno (SBR) & Butadiene $\{$ GLO\}, Ecoinvent v3.3 \\
\hline Eletricidade para mistura & Electricity, medium voltage $\{$ BR $\}$, Ecoinvent v3.3 \\
\hline Transporte materiais e resíduos & $\begin{array}{l}\text { Transport, freight, lorry } 16-32 \text { metric ton, EURO3 }\{G L O\}, \\
\text { Ecoinvent v3.3 }\end{array}$ \\
\hline Aterro resíduos inerte & $\begin{array}{l}\text { Inert waste, for final disposal }\{\text { RoW\} } \text { treatment of inert } \\
\text { waste, inert material landfill, Ecoinvent v3.3 }\end{array}$ \\
\hline
\end{tabular}

Tabela 3 - Parâmetros utilizados na modelagem dos diferentes processos de execução dos revestimentos de argamassa

\begin{tabular}{|c|c|c|c|}
\hline Tipo de execução & $\begin{array}{c}\text { Consumo } \\
\text { real }^{1} \\
\left(\mathbf{m}^{3} / \mathbf{m}^{2} \cdot \mathbf{c m}\right) \\
\end{array}$ & $\begin{array}{l}\text { Consumo de energia } \\
\text { elétrica para } \\
\text { execução }\left(\mathrm{kWh} / \mathrm{m}^{2}\right)\end{array}$ & $\begin{array}{c}\text { Quantidade de } \\
\text { material } \\
\text { descartado }\left(\mathrm{m}^{3} / \mathrm{m}^{2}\right)\end{array}$ \\
\hline Chapisco - Convencional & 0,008 & 0,0023 & 0,0032 \\
\hline Chapisco - Rolado & 0,003 & 0,0023 & 0,0003 \\
\hline Camada única - Convencional & 0,016 & 0,0069 & 0,006 \\
\hline Camada única - Projetada & 0,011 & 0,0890 & 0,002 \\
\hline
\end{tabular}

Fonte: com base nos dados de Albuquerque, Lira e Sposto (2018).

Nota: ${ }^{1}$ foi considerado o volume com densidade da argamassa de $1.900 \mathrm{~kg} / \mathrm{m}^{3}$ (ABNT, 2005). 
Para uma camada de argamassa de pequena espessura e exposta, como rebocos, o processo de carbonatação é considerado rápido e completado dentro de um ano (PITTAU et al., 2018). Para a quantificação do $\mathrm{CO}_{2}$ absorvido durante esse 1 ano utilizou-se a Equação 1, retirada de Collins (2010). Adotou-se que o teor de $\mathrm{CaO}$ no cimento CPII-E-32 é de 0,55, e de 0,70 na cal hidratada CHI, a partir de dados de fabricantes. Assumiu que $75 \%$ do $\mathrm{CaO}$ é convertido em carbonato de cálcio (LAGERBLAD, 2005). A relação entre as massas molares de $\mathrm{CO}_{2} / \mathrm{CaO}$ é de 0,79 .

$m_{\mathrm{CO} 2}=\left(\frac{x(t)}{1000}\right) \times A \times\left(c_{\text {cim } x} x \mathrm{CaO}_{\text {cim }}+c_{\text {cal }} \times \mathrm{CaO}_{\text {cal }}\right) \times r \times\left(\frac{M_{\mathrm{CO} 2}}{M_{\mathrm{CaO}}}\right)$

Eq. 1

Onde:

$\mathrm{m}_{\mathrm{CO} 2}$ é a massa de $\mathrm{CO}_{2}$ sequestrada pela carbonatação em um tempo $\mathrm{t}(\mathrm{kg})$;

$\mathrm{x}(\mathrm{t})$ é a profundidade da argamassa carbonatada no tempo $\mathrm{t}(\mathrm{mm})$;

A é a área superficial exposta $\left(\mathrm{m}^{2}\right)$;

$\mathrm{c}_{\mathrm{cim}}$ é a quantidade de cimento Portland na argamassa $\left(\mathrm{kg} / \mathrm{m}^{3}\right)$;

$\mathrm{CaO}_{\text {cim }}$ é o teor de $\mathrm{CaO}$ na composição do cimento Portland;

$\mathrm{c}_{\mathrm{cal}}$ é a quantidade de cal hidratada na argamassa $\left(\mathrm{kg} / \mathrm{m}^{3}\right)$;

$\mathrm{CaO}_{\text {cal }}$ é o teor de $\mathrm{CaO}$ na composição do cimento Portland;

r é a proporção de $\mathrm{CaO}$ que é convertida em carbonato de cálcio ( $\mathrm{CaCO} 3)$;

$\mathrm{MM}_{\mathrm{CO} 2}$ é a massa molar do $\mathrm{CO}_{2}(\mathrm{~g} / \mathrm{mol})$; e

$\mathrm{MM}_{\mathrm{CaO}}$ é a massa molar do $\mathrm{CaO}(\mathrm{g} / \mathrm{mol})$.

A quantidade de $\mathrm{CO}_{2}$ absorvido pelo processo de carbonatação foi contabilizada como valor negativo na categoria de potencial de aquecimento global (GWP100). Como a carbonatação tem influência das condições locais de exposição e composição dos revestimentos, foi realizada análise de sensibilidade considerando três espessuras de frentes de carbonatação para 1 ano: $10 \mathrm{~mm}, 15 \mathrm{~mm}$ e $25 \mathrm{~mm}$ no revestimento de camada única (de ambos os lados da vedação). O processo de carbonatação foi contabilizado duas vezes, sendo o primeiro quando o revestimento é executado no início de seu ciclo de vida e, posteriormente, após sua reposição.

Para a etapa de reposição adotaram-se os mesmos processos apresentados para a produção, transporte e execução do revestimento. Para o fim de vida adotou-se que o revestimento é destinado a um aterro de resíduos inertes, assumindo as distâncias apresentadas anteriormente.

\section{Avaliação do Impacto do Ciclo de Vida}

O método de avaliação do impacto do ciclo de vida (AICV) CML linha de base IA, versão 3.03, foi escolhido neste estudo. Foram consideradas as categorias de impacto ambiental potencial de aquecimento global (GWP100), redução da camada de ozônio (ODP), acidificação (AP), eutrofização (EP), potencial de oxidação fotoquímica (POCP), depleção abiótica de elementos (ADP-e) e combustíveis fósseis (ADP-ff), de acordo com a EN 15804 (EUROPEAN..., 2012). A modelagem foi realizada no software SimaPro v8.5 e em planilha eletrônica do Microsoft Excel.

\section{Resultados e discussões}

\section{Avaliação das argamassas}

Nas Figuras 2, 3 e 4 são apresentados os resultados dos potenciais impactos ambientais do chapisco (convencional e rolado) e camada única, e na Figura 5 o perfil ambiental dessas argamassas, considerando o volume produzido (em metros cúbicos). 
Figura 2 - Comparação dos potenciais impactos ambientais das argamassas de chapisco convencional (por metro cúbico) considerando as distâncias intermediárias de transporte - (A) Potencial de aquecimento global; (B) Potencial de depleção da camada de ozônio; (C) Acidificação; (D) Eutrofização; (E) Formação de foto-oxidantes; (F) Depleção abiótica de elementos; (G) Depleção abiótica de combustíveis fósseis

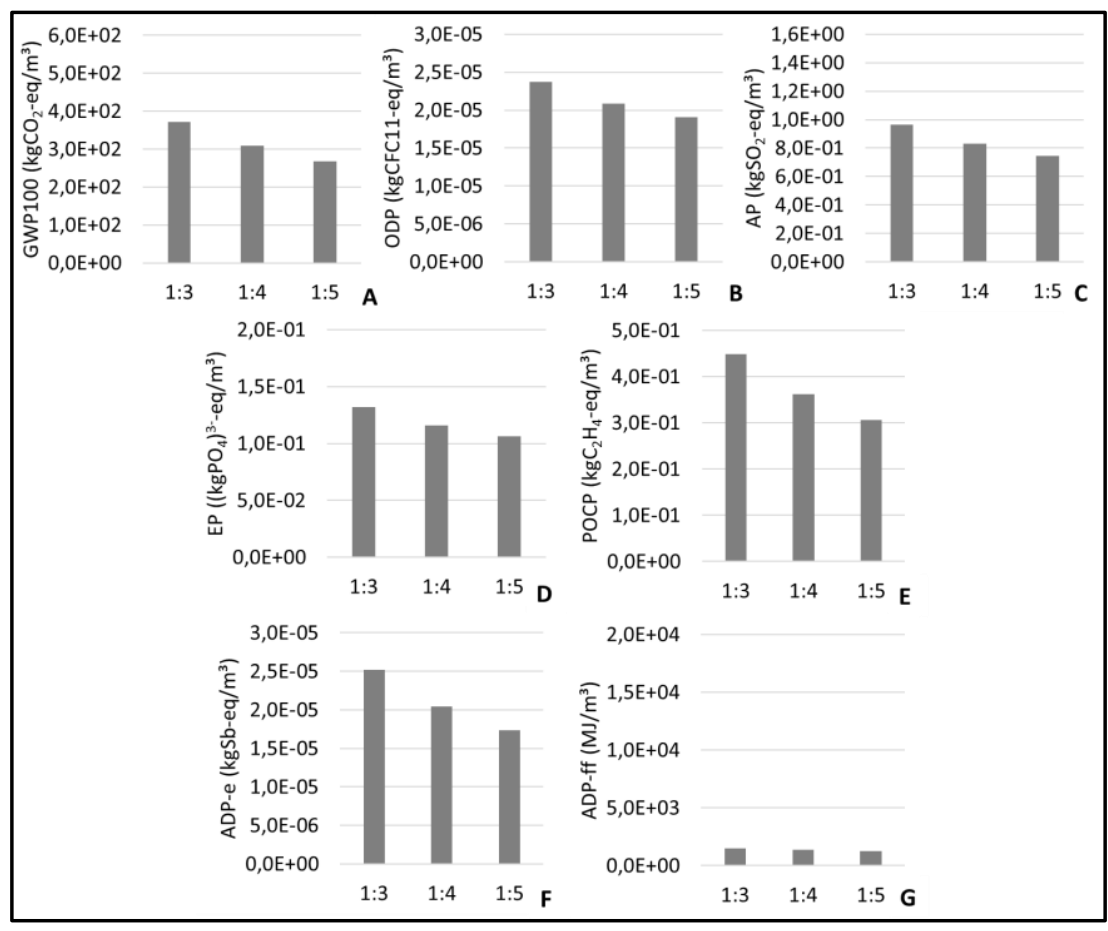

Figura 3 - Comparação dos potenciais impactos ambientais das argamassas de chapisco rolado (por metro cúbico) considerando as distâncias intermediárias de transporte; (A) Potencial de aquecimento global; (B) Potencial de depleção da camada de ozônio; (C) Acidificação; (D) Eutrofização; (E) Formação de foto-oxidantes; (F) Depleção abiótica de elementos; (G) Depleção abiótica de combustíveis fósseis

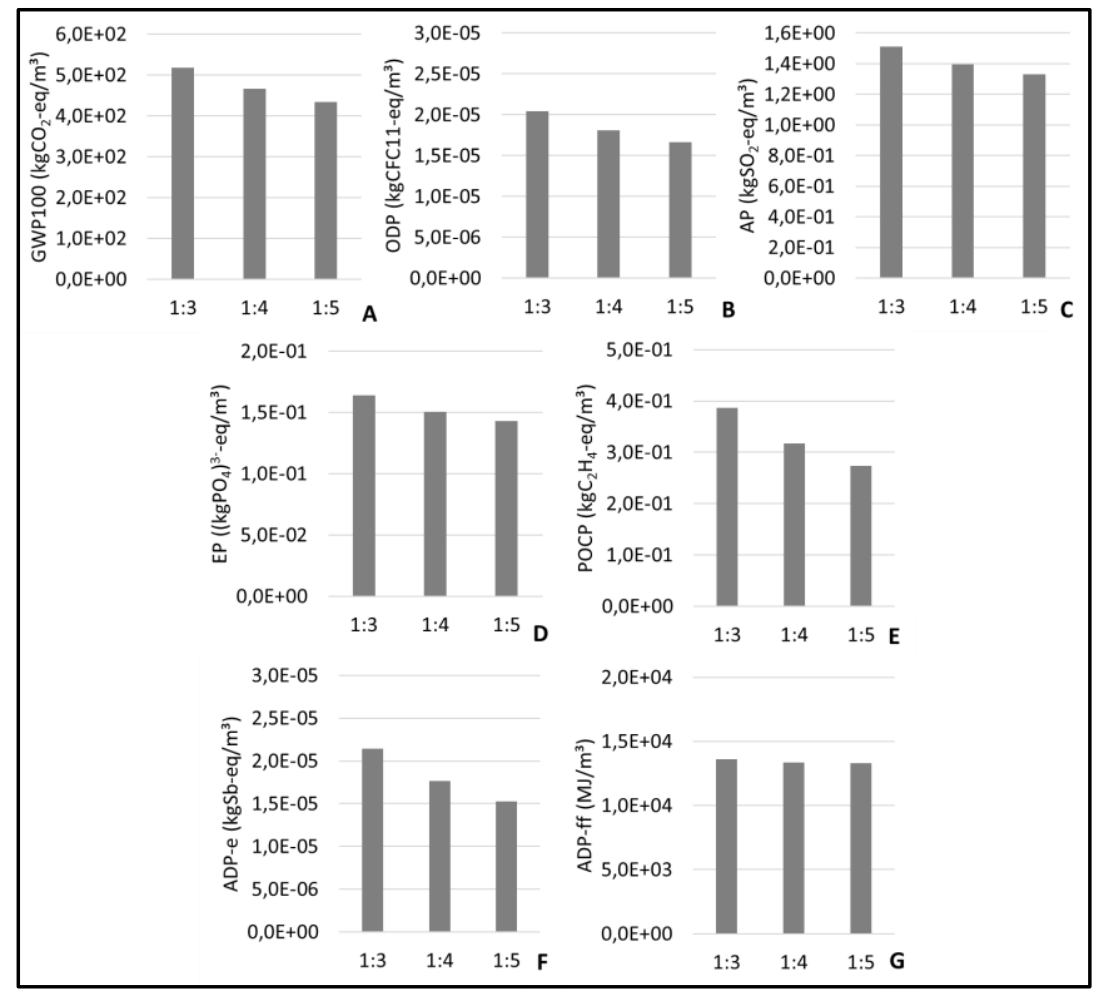


Figura 4 - Comparação dos potenciais impactos ambientais das argamassas de camada única (por metro cúbico) considerando as distâncias intermediárias de transporte - (A) Potencial de aquecimento global; (B) Potencial de depleção da camada de ozônio; (C) Acidificação; (D) Eutrofização; (E) Formação de foto-oxidantes; (F) Depleção abiótica de elementos; (G) Depleção abiótica de combustíveis fósseis

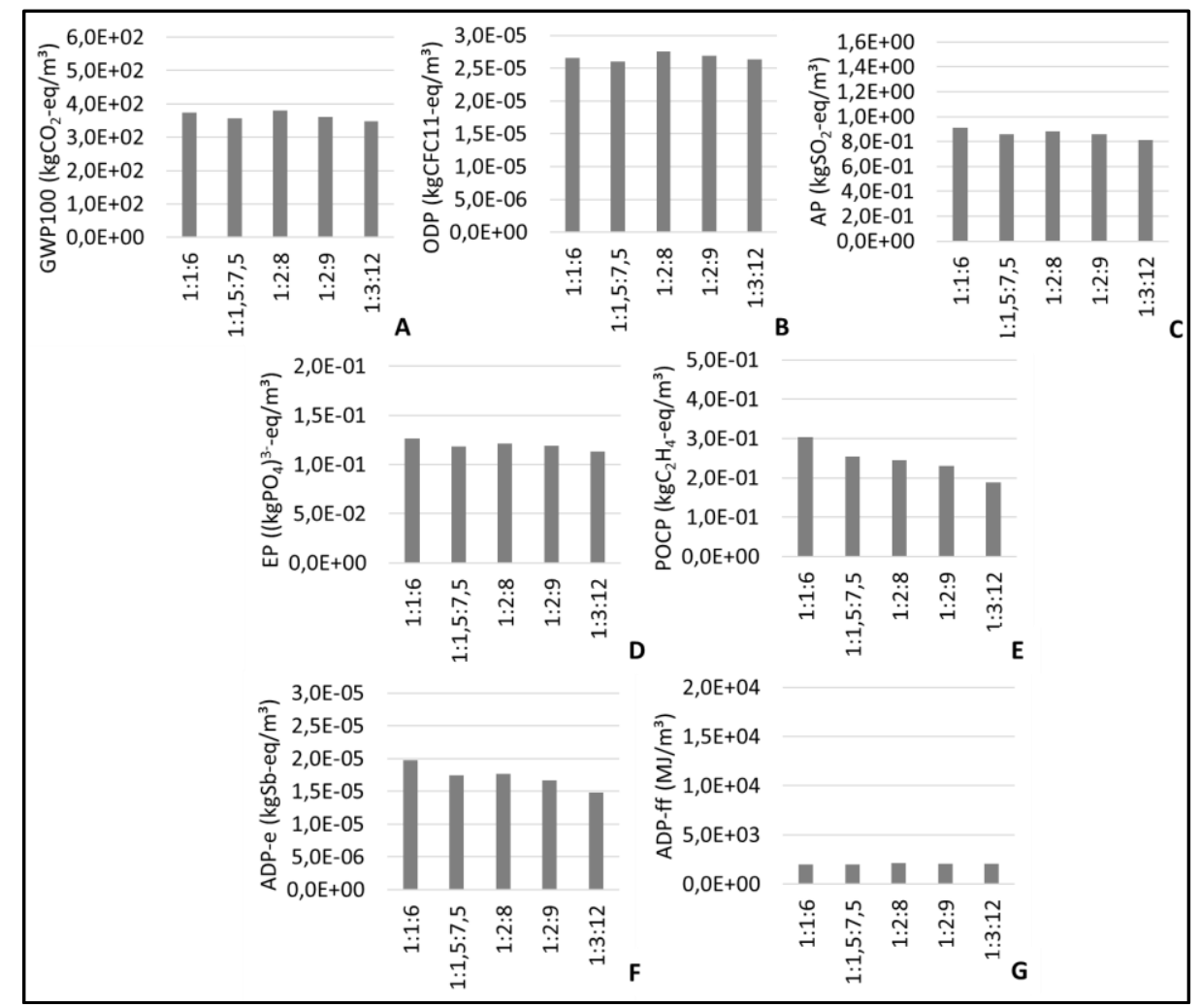

Figura 5 - Perfil ambiental para a produção das argamassas de chapisco convencional, rolado e camada única - (A) Chapisco convencional com traço 1:3; (B) Chapisco convencional com traço 1:5; (C) Chapisco rolado com traço 1:3; (D) Chapisco rolado com traço 1:5; (E) Argamassa de camada única com traço 1:1:6; (F) Argamassa de camada única com traço 1:3:12

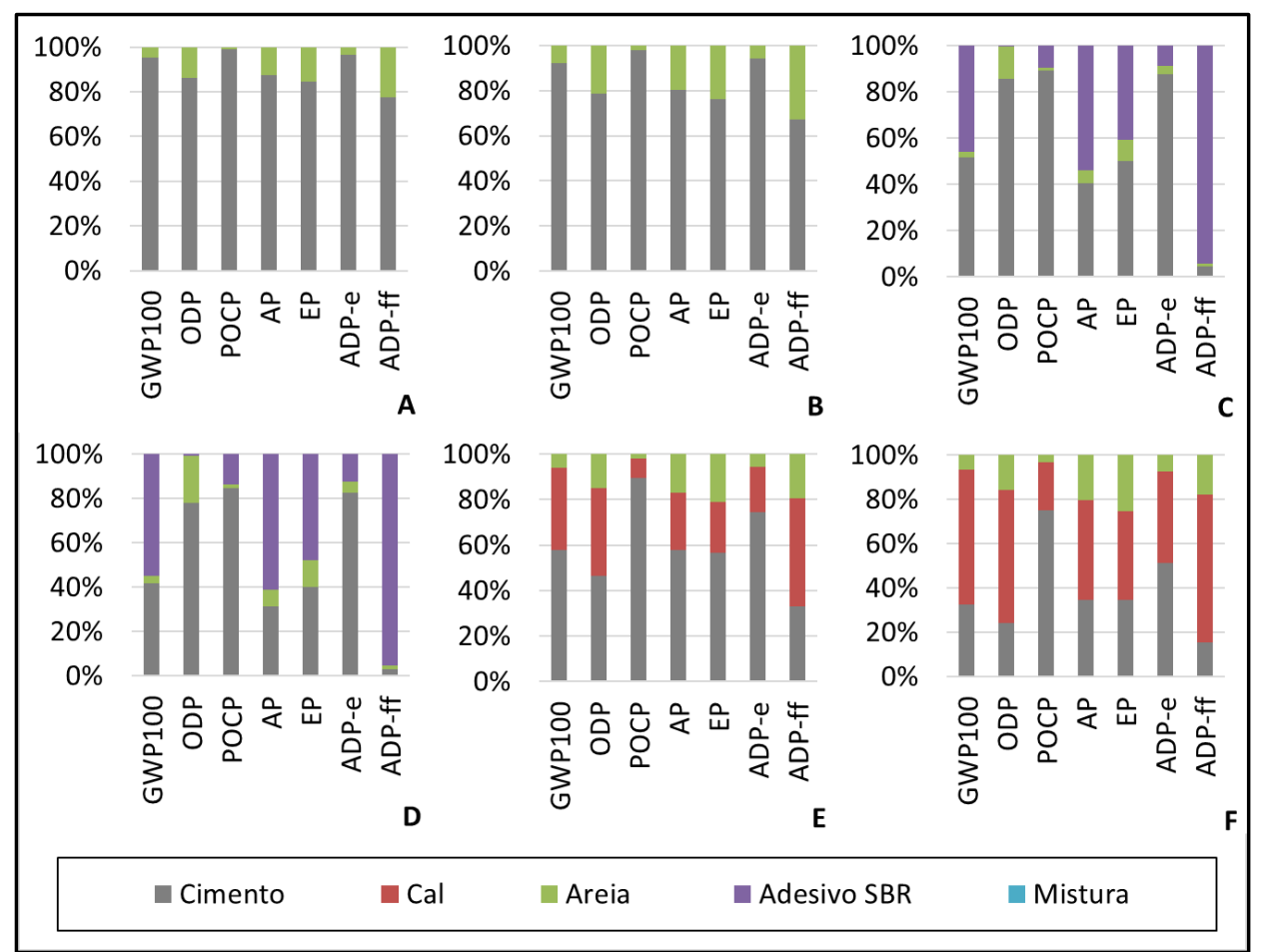


Para o chapisco convencional fica claro que os impactos ambientais aumentam com o acréscimo do teor de cimento na mistura (traços mais ricos, como o 1:3), resultado também observado por Caldas et al. (2016). Para o chapisco rolado, esse comportamento também ocorre; no entanto, a diferença entre eles é menor, pois os impactos do butadieno ajudam a equilibrar os resultados finais, já que são utilizadas quantidades bem próximas desse material para os três traços. A produção de $1 \mathrm{~m}^{3}$ de chapisco rolado tem maiores impactos ambientais que o chapisco convencional devido à presença do butadieno principalmente para a categoria de ADP-ff, com a diferença de uma ordem de grandeza, e outras como GWP100, AP e EP.

Os traços da camada única não se comportam da mesma forma. $\mathrm{O}$ traço 1:1:6 (mais rico) não foi o mais impactante para todas as categorias, o que se deve ao fato de o aumento do teor de cal hidratada na mistura resultar em aumentos para algumas categorias de impacto. O traço 1:2:8 apresenta maior impacto para algumas categorias GWP100, ODP, ADP-e e ADP-ff. Por outro lado, o traço 1:3:12 (mais pobre) apresentou menor impacto para a maioria das categorias.

Para a argamassa de chapisco convencional, o cimento é o insumo mais impactante para os três traços avaliados e para a maioria das categorias de impacto. Para o chapisco rolado, o cimento e o butadieno são os insumos mais impactantes. Especificamente para GWP100 e ADP-ff, o butadieno tem grande contribuição, que se deve ao grande consumo de energia fóssil para sua produção. Para a argamassa de camada única, o cimento foi o insumo mais impactante para as categorias GWP100, AP, EP e POPC nos traços mais ricos, como 1:1:6 e 1:1,5:7,5, enquanto a cal começa a ser mais impactante para traços mais pobres, como 1:3:9 e $1: 3: 12$.

Os impactos do cimento se devem principalmente à produção do clínquer (sobretudo relacionado ao processo de calcinação para o GWP100) e queima de combustíveis fósseis utilizados em sua produção, havendo no Brasil grande utilização de coque de petróleo. Os impactos do butadieno se devem principalmente ao grande consumo de energia necessária para sua produção. Os impactos da cal estão majoritariamente relacionados a sua extração, normalmente com explosivos, e também ao processo de calcinação, que utiliza combustíveis fósseis. A areia tem seus impactos atribuídos a sua extração, que utiliza equipamentos a diesel. $\mathrm{O}$ transporte impacta devido à queima de diesel, que aumenta com distâncias mais longas e/ou mais material consumido.

Os resultados apresentados diferem de Condeixa, Haddad e Boer (2014), principalmente devido aos dados utilizados no inventário. Nesse estudo os dados foram retirados todos do Ecoinvent v3.0, além de ser considerado areia silicosa, o que fez o impacto da areia aumentar consideravelmente quando comparado ao uso de areia natural, que foi a adotada no presente estudo. Por outro lado, esses autores também verificaram grande participação da cal hidratada nos impactos ambientais. Os resultados estão bem próximos dos apresentados por Caldas e Toledo Filho (2018), que também utilizaram o banco de dados do Sinapi e dados similares no inventário do ciclo de vida.

\section{Avaliação dos revestimentos argamassados}

Quando a combinação das diferentes argamassas é avaliada em termos do revestimento (em metros quadrados) em conjunto com diferentes processos de execução, foram obtidos os resultados apresentados nas Figuras 6, 9, 10,11, 12, 13 e 14. O intervalo de variação presente nas figuras (pelas barras de incerteza) está relacionado com a variação das distâncias de transporte considerados, calculadas com base no desvio padrão dos cenários avaliados.

É possível observar que as combinações com chapisco com traço mais rico (1:3), na cor cinza, são mais impactantes para a maioria das categorias de impacto avaliadas. O traço 1:2:8 de camada única foi o mais impactante para as categorias GWP100, ODP e ADP-ff, enquanto o traço 1:1:6, para AP, EP, POCP e ADPe, o que ocorreu devido ao elevado consumo de cimento CPII e cal hidratada quando comparado aos outros traços. Quando se aumenta a participação de areia na mistura, os impactos começam a decrescer, já que o processo de obtenção de areia é muito menos intensivo que a produção de cimento e cal.

Esse comportamento só não é observado para a categoria ADP-e, que considera que a exaustão de areia natural tem maior impacto que a exaustão dos elementos normalmente utilizados para fabricação de cimento e cal, normalmente calcário e argila. A variação nas distâncias de transporte (representada pelas barras de erros) mostrou que, para a maioria das categorias de impacto, ela tem grande influência nos resultados, sendo, portanto, importante avaliá-las. 
Figura 6 - Potencial de aquecimento global (GWP100) dos revestimentos avaliados - (A) Processo convencional; (B) Processo rolado e projetado

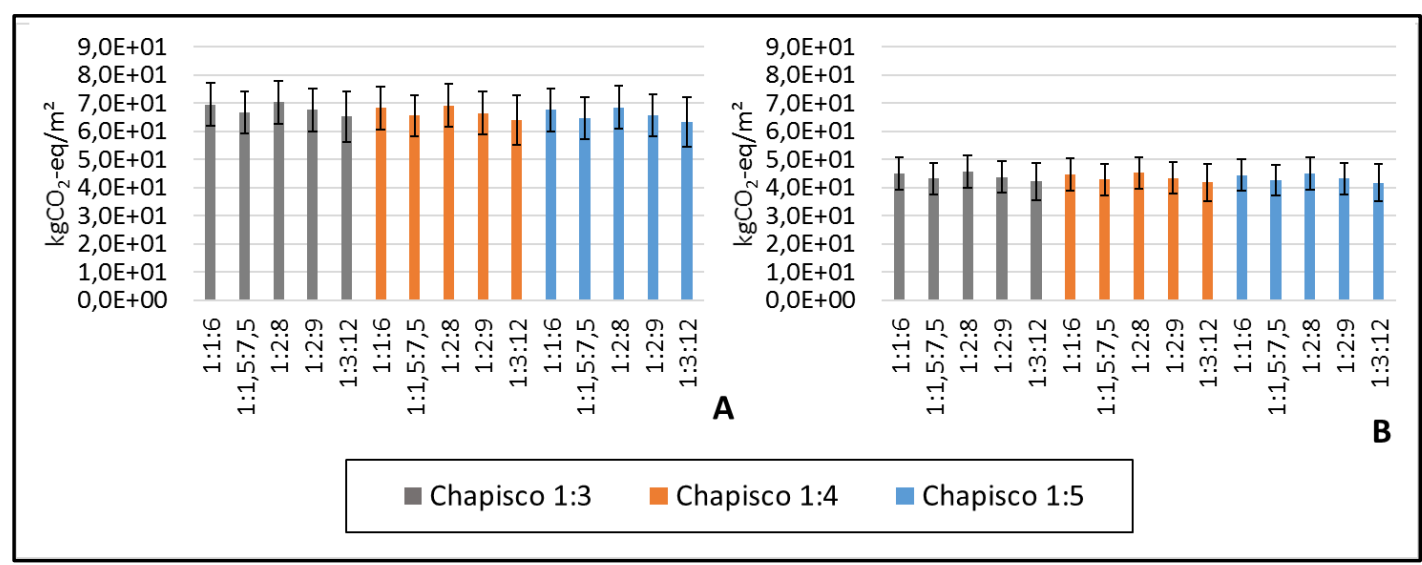

Figura 7 - Potencial de Depleção da Camada de Ozônio (ODP) dos revestimentos avaliados - (A) Processo convencional; (B) Processo rolado e projetado

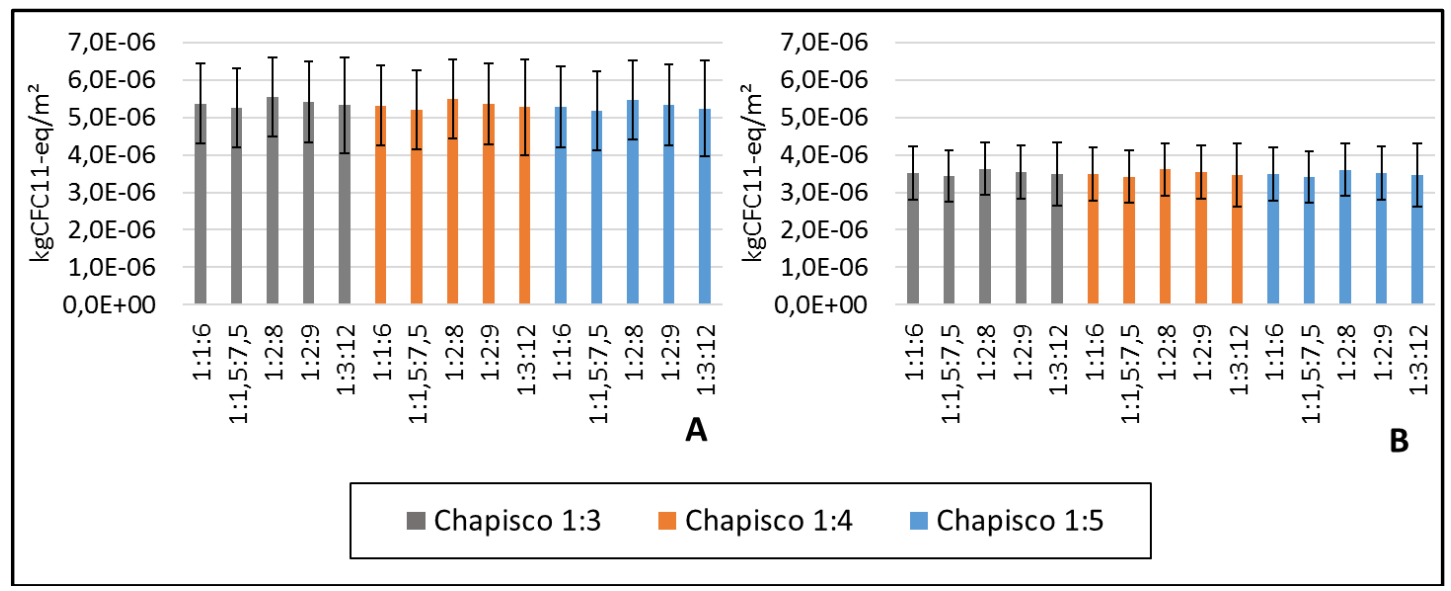

Figura 8 - Potencial de acidificação (AP) dos revestimentos avaliados - (A) Processo convencional; (B) Processo rolado e projetado

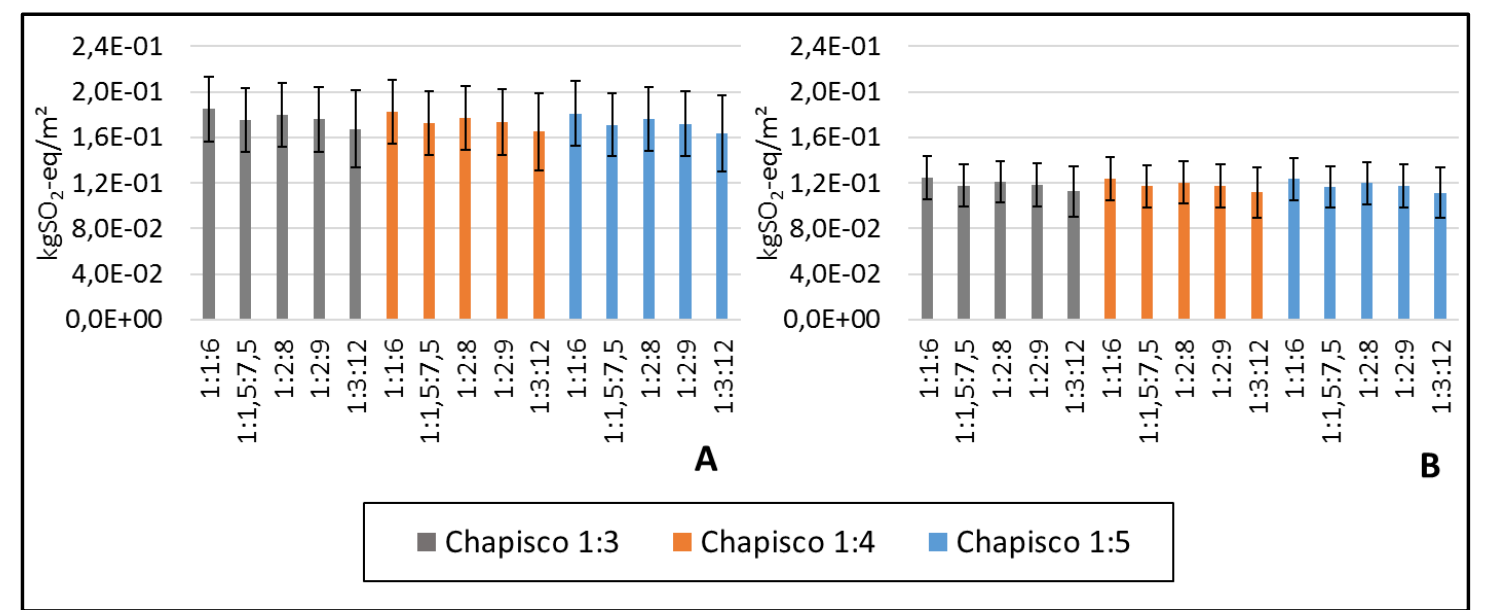


Figura 9 - Potencial de eutrofização (EP) dos revestimentos avaliados - (A) Processo convencional; (B) Processo rolado e projetado

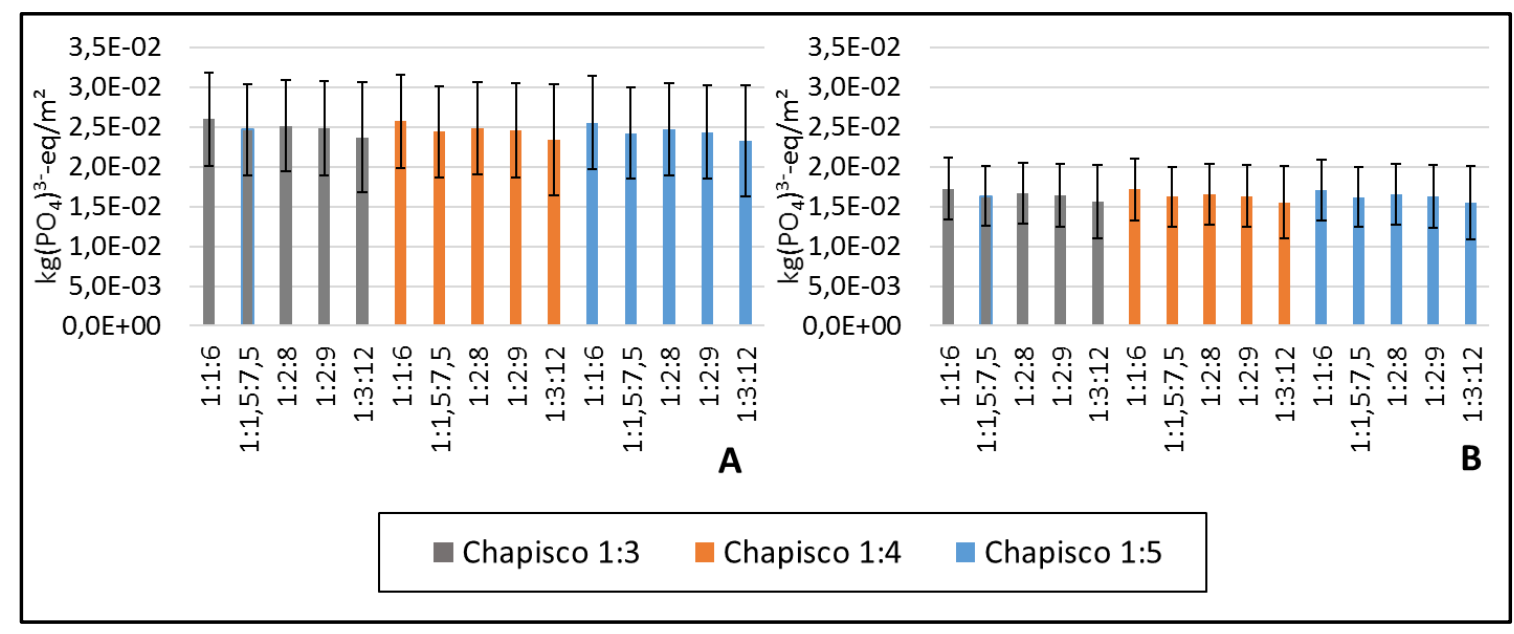

Figura 10 - Potencial de formação de foto-oxidantes (POCP) dos revestimentos avaliados - (A) Processo convencional; (B) Processo rolado e projetado

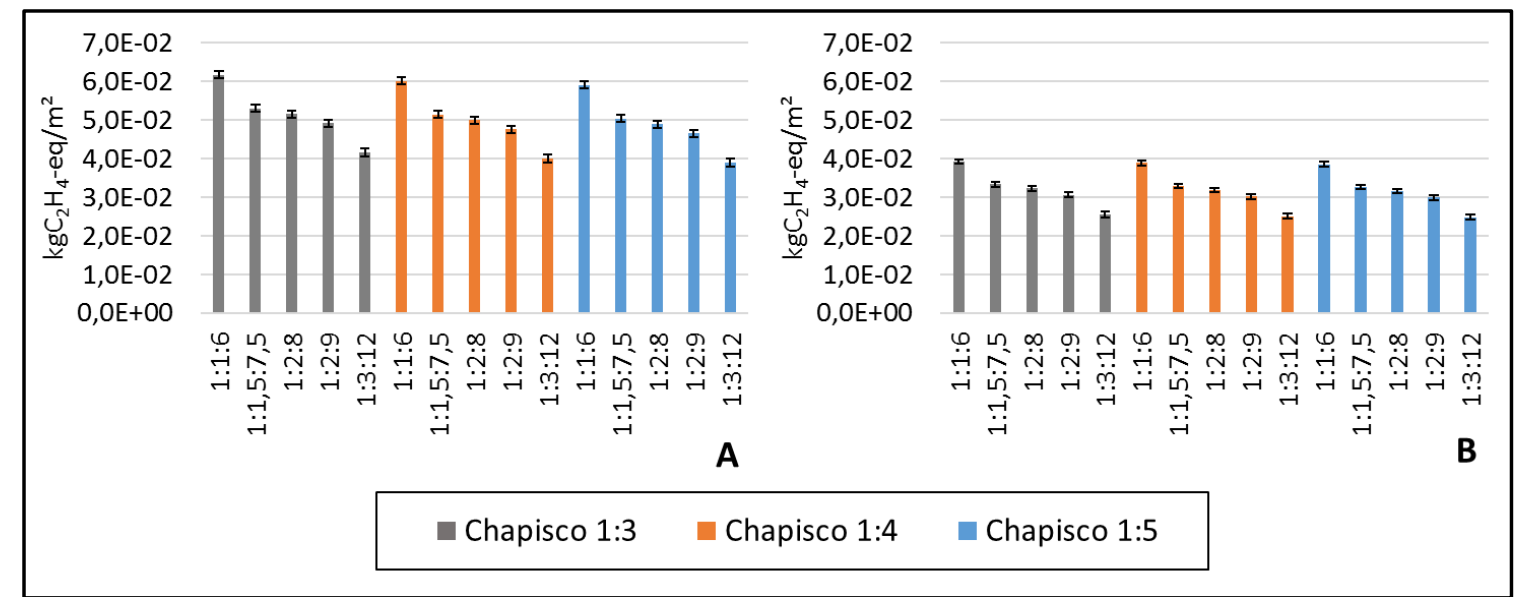

Figura 11 - Potencial de depleção de elementos (APD-e) dos revestimentos avaliados - (A) Processo convencional; (B) Processo rolado e projetado

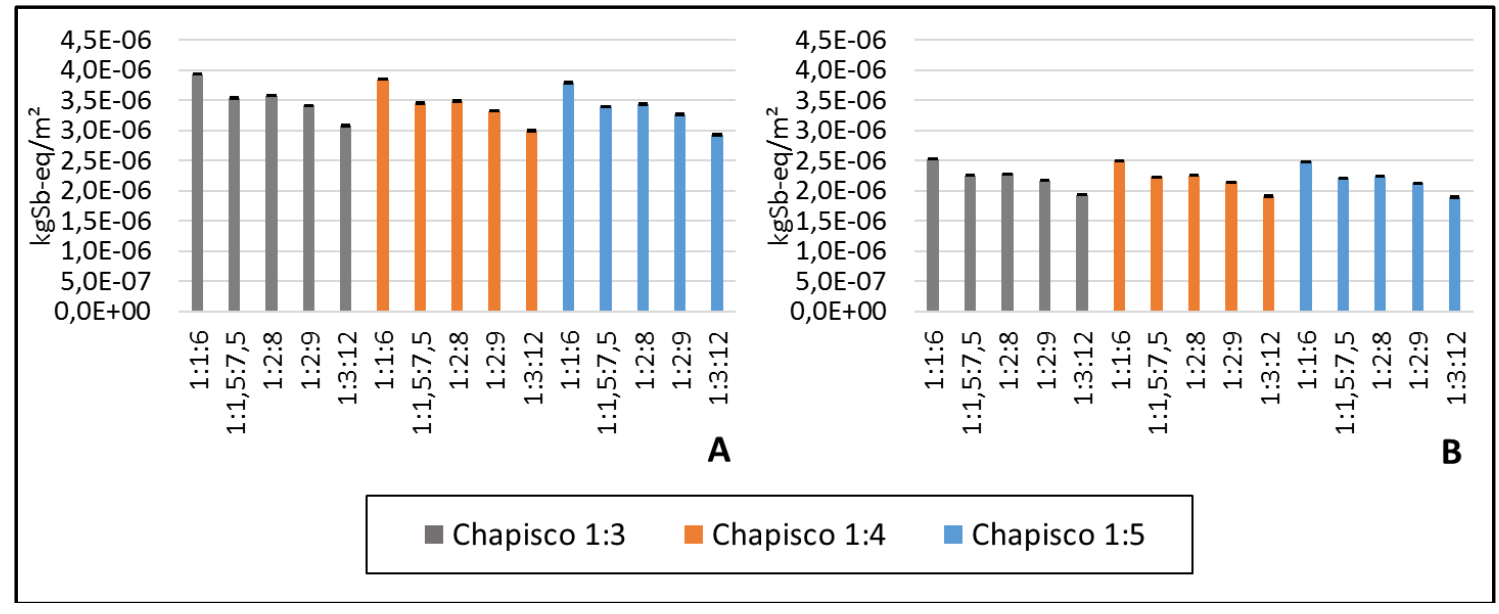


Figura 12 - Potencial de depleção de combustíveis fósseis (APD-ff) dos revestimentos avaliados - (A) Processo convencional; (B) Processo rolado e projetado

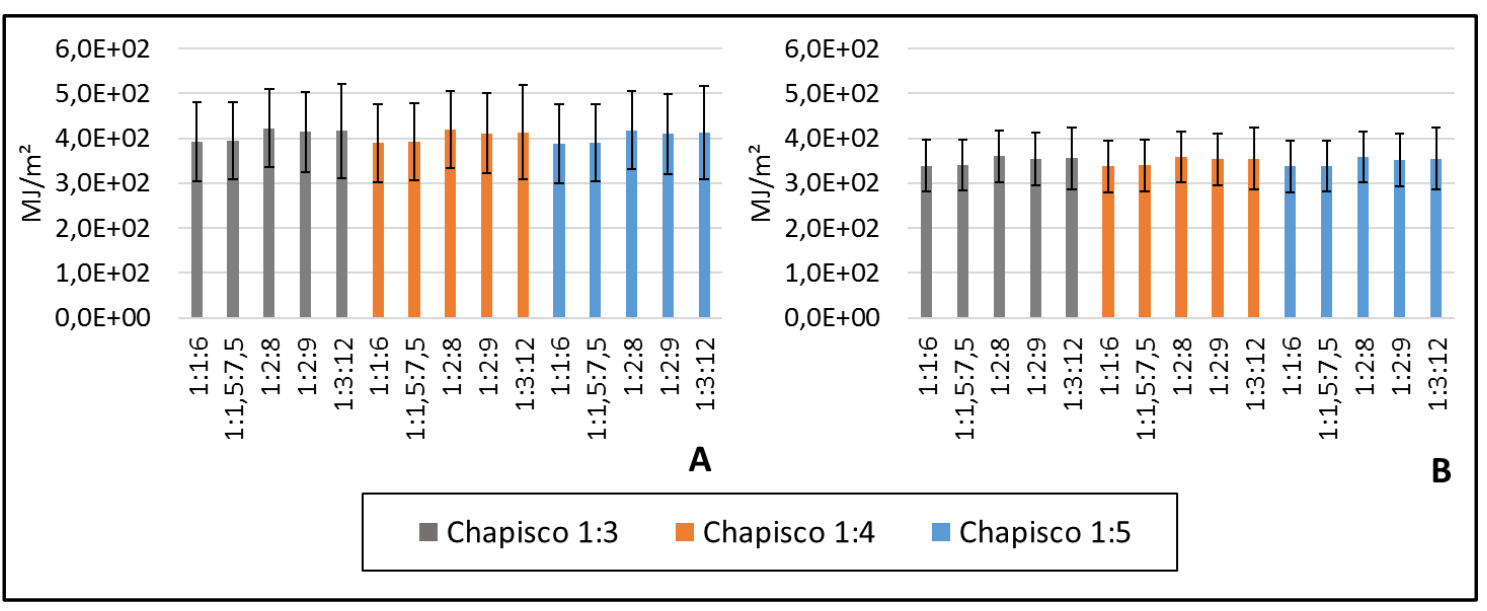

Nessa ótica, pensando somente na redução de potenciais impactos ambientais, e considerando os dados utilizados nesta pesquisa, a combinação de chapisco 1:5 e camada única 1:3:12 tende a ser a menos impactante e, portanto, deve ter seu uso incentivado, isto é, quando for possível diante das realidades do local, condições de construção e requisitos de desempenho e durabilidade.

Quando o processo executivo é avaliado, a técnica de chapisco rolado e camada única projetada consegue reduzir consideravelmente os impactos ambientais, entre 15\% (ADP-ff) e 64\% (POCP). Isso ocorre pela redução do consumo de material, que foi de $45 \%$ entre os dois métodos para a camada única e de $63 \%$ para o chapisco. Essa relação mostra que são diretamente proporcionais e que, portanto, exercem maior influência para a redução dos impactos ambientais que o traço da argamassa utilizada. A diferença é baixa especificamente quanto à categoria ADP-ff devido ao elevado impacto do butadieno utilizado no chapisco rolado. Como a camada única é mais espessa que o chapisco (cinco vezes superior), ela exerce maior influência nos resultados finais. Embora o chapisco rolado possua maior impacto por metro cúbico que o chapisco convencional, aquele resulta em menores impactos ambientais quando é aplicado no revestimento, em metro quadrado, pois seu consumo é menor.

A produção dos insumos utilizados na confecção da argamassa e seu transporte para o canteiro de obras respondem por quase todos os impactos ambientais das etapas avaliadas. A mistura e a destinação das perdas têm impactos insignificantes (menor que 2\%) para todas as categorias avaliadas, também verificado por Albuquerque, Lira e Sposto (2018) para o impacto de potencial de aquecimento global. Especificamente para a categoria GWP100, a carbonatação exerce participação considerável, como é apresentado na Figura 13.

Os pontos da Figura 13 representam o balanço do impacto de GWP100 quando o processo de carbonatação é considerado em todo o ciclo de vida do revestimento (representados pelas barras negativas em verde). Enquanto as barras de incerteza se referem às diferentes espessuras de frente de carbonatação consideradas no revestimento, observou-se que, quando a carbonatação é contabilizada, há a possibilidade de diminuir o impacto de GWP100 em até $16 \%$ para o caso da argamassa projetada e em até $11 \%$ para a de processo convencional. Diferentemente do que ocorre para estruturas de concreto, em que a carbonatação leva à despassivação e à corrosão da armadura (MEHTA; MONTEIRO, 2014), para argamassas (sem reforço metálico) ela tem um efeito benéfico, pois, além de capturar o $\mathrm{CO}_{2}$ atmosférico, traz melhorias em termos de durabilidade e desempenho mecânico por fechar os poros e aumentar a resistência da argamassa utilizada no revestimento. Portanto, recomenda-se que o $\mathrm{CO}_{2}$ capturado via carbonatação seja quantificado nos estudos de ACV aplicados às argamassas.

A reposição do revestimento representa aproximadamente $50 \%$ dos impactos de seu ciclo de vida para a maioria das categorias de impacto avaliadas, já que foi considerada apenas uma reposição na vedação vertical e com os materiais provenientes dos mesmos locais adotados na etapa de construção. O envio e destinação final do material reposto para o aterro representou contribuição inferior a $3 \%$ para todas as categorias de impacto. A etapa de fim de vida também se mostrou desprezível (menor que $2 \%$ ), sendo a maior parcela dessa etapa no transporte dos resíduos. 
Figura 13 - Influência do processo de carbonatação para a categoria de potencial de aquecimento global - GWP100 para o cenário de distâncias de transporte intermediário -(A) Processo convencional; (B) Processo rolado e projetado

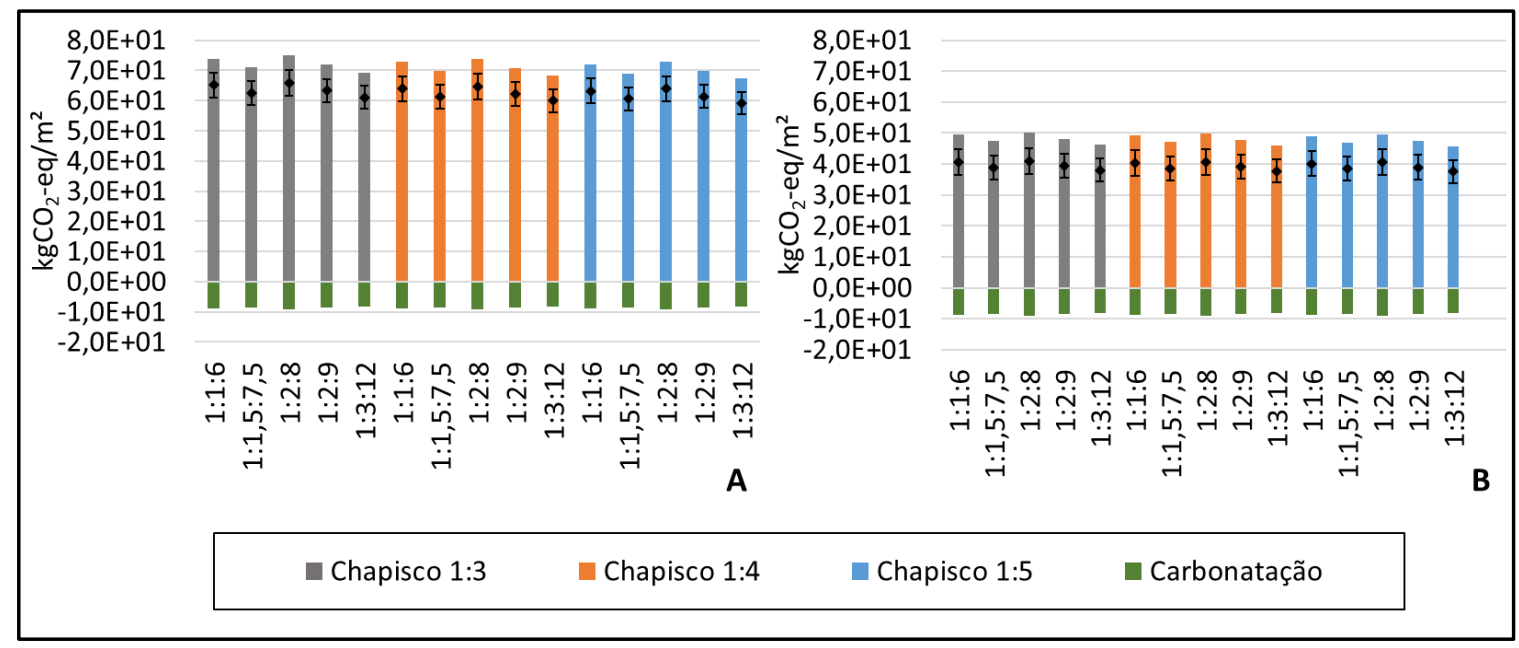

\section{Diretrizes ambientais para a redução dos impactos dos revestimentos argamassados}

Com base nos resultados encontrados e na literatura pesquisada, descritos anteriormente, foram propostas algumas diretrizes ambientais, apresentadas na Figura 14, para a redução dos impactos dos revestimentos argamassados executados no Brasil.

As diretrizes foram classificadas em quatro níveis, sendo as de números 1 e 4 a mais e a menos impactante respectivamente para a redução dos impactos ambientais dos revestimentos argamassados.

Os resultados de Caldas et al. (2016) corroboram a primeira estratégia, pois verificaram que a técnica de chapisco rolado tem expressivas reduções de emissões de $\mathrm{CO}_{2}$-eq $(80 \%)$ em relação ao chapisco convencional, devido ao menor consumo de material da primeira técnica, embora para algumas categorias de impacto, como a ADP-ff, a diferença nos impactos pode ser bem inferior, como foi verificado aqui, de $8 \%$, devido ao alto impacto do adesivo de butadieno para essa categoria.

Albuquerque, Lira e Sposto (2018) também verificaram resultado similar entre processos de produção projetado e convencional considerando argamassa estabilizada e ensacada respectivamente, no entanto esses autores não avaliaram a etapa de reposição e fim de vida do revestimento. Quando essa etapa é avaliada, a diferença entre os processos de execução aumenta ainda mais, isto é, se for assumido que a reposição ocorrerá com o mesmo revestimento e mesmo processo executivo empregado durante a etapa de construção da vedação. Essas estratégias podem ser consideradas uma forma de desmaterialização e de eficientização da construção, pois menor quantidade de material é consumida para o fornecimento de um mesmo serviço ou similar, mas que seja adequado à função. De certa forma, esses achados já eram esperados, tendo em vista que menor consumo de materiais e perdas no processo levam a impactos proporcionalmente menores.

Para a redução dos impactos na formulação da argamassa, o foco deve ser na redução dos ligantes, cimento e cal. Cirilo (2018) verificou que a argamassa industrializada emite $50 \%$ menos $\mathrm{CO}_{2}$-eq que argamassas rodadas em obra devido principalmente à maior eficiência do sistema de produção, que consome menos cimento, e pelo fato de não ser utilizada cal na formulação. Gama Júnior (2013) vai ao encontro desses resultados mostrando que a argamassa industrializada emite menos $\mathrm{CO}_{2}$ que argamassas rodadas em obra, no entanto com uma diferença aproximada de 30\%. Também atribui essa redução aos mesmos motivos apresentados por Cirilo (2018). O uso de aditivos químicos, como incorporadores de ar, pode melhorar o desempenho da argamassa com redução desses insumos (GAMA JÚNIOR, 2013; ROMANO; CINCOTTO; PILEGGI, 2018). Portanto, a industrialização da produção de argamassa é outro caminho importante para a redução dos impactos ambientais do setor. 
Figura 14 - Classificação de diretrizes para redução dos impactos ambientais dos revestimentos argamassados no Brasil

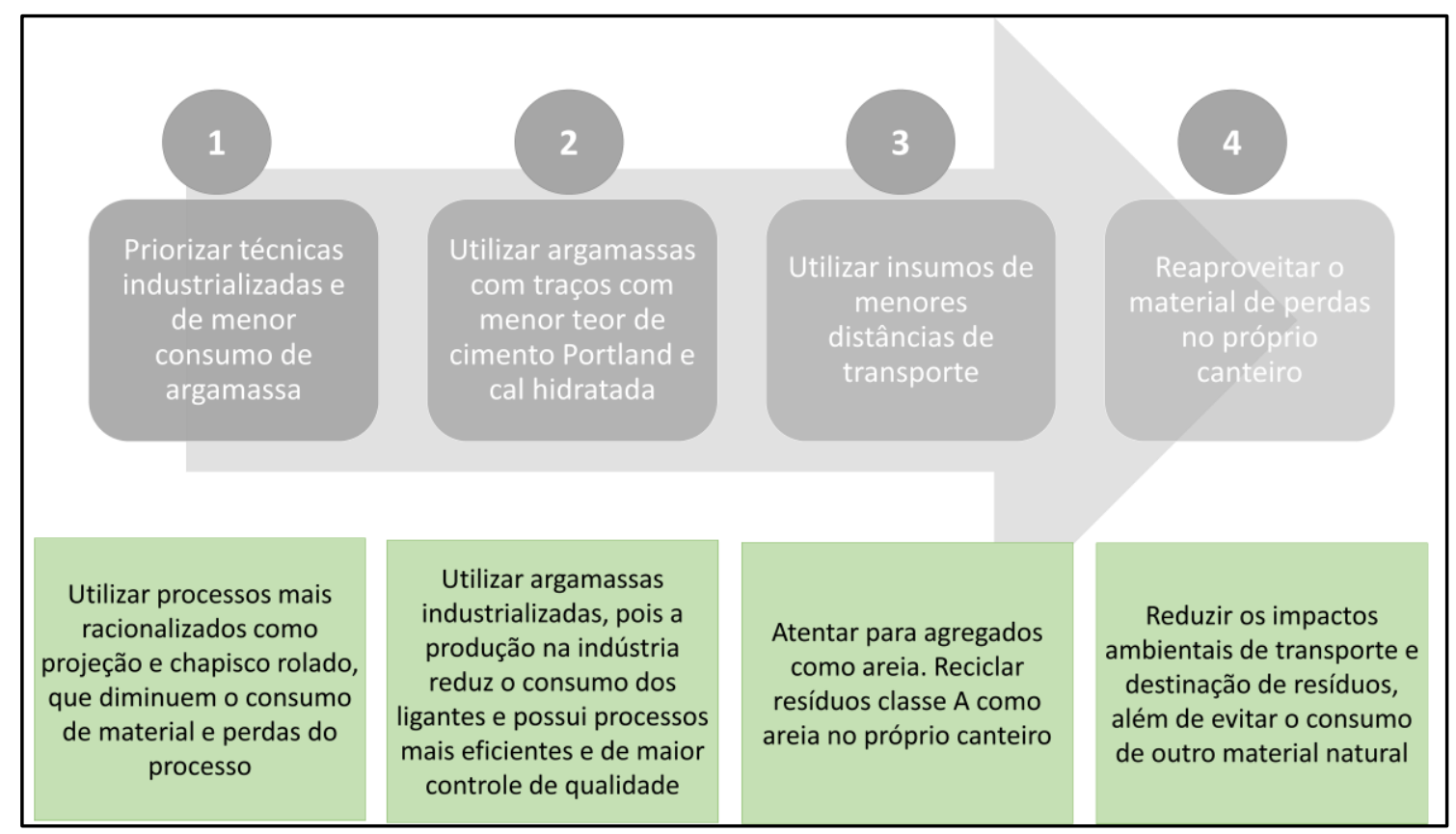

Entretanto, para isso é importante ressaltar que a diminuição no teor dos materiais mais impactantes, cimento e cal, tende a influenciar diretamente no desempenho do revestimento. O cimento está diretamente relacionado à resistência mecânica, e a cal, à plasticidade e à deformabilidade. Traços mais ricos podem gerar argamassas mais resistentes, mas ao mesmo tempo muito rígidas, que, dependendo da aplicação e da condição climática, podem levar a menor durabilidade e maior número de manutenções e impactos ambientais. Já traços mais pobres podem levar a argamassas de baixa resistência, alta porosidade e outros fatores que também podem resultar em baixa durabilidade (CARASEK, 2010). Dessa forma, cabe ao especificador da argamassa ter em mente que esses são os materiais de maior impacto ambiental e que seu uso deve ser dosado de acordo com as necessidades de onde a argamassa será aplicada.

Outra estratégia que vem sendo cada vez mais encontrada nas pesquisas é o uso de materiais alternativos, em sua grande maioria, resíduos em substituição ao cimento Portland para a produção de argamassas, como apontam De Paula et al. (2018), que mostraram ser possível produzir argamassas com resíduos de cerâmica vermelha com menor impacto e melhor desempenho mecânico e durabilidade que argamassas de cimento e areia.

Internacionalmente, algumas pesquisas têm mostrado que é possível produzir argamassas mais eficientes do ponto de vista energético com o uso de resíduos de cortiça, como apontam Brás e Gomes (2015). Teixeira et al. (2019) verificaram a viabilidade técnica e ambiental do uso de cinzas volantes de biomassa para a produção de argamassas.

O transporte pode ser uma etapa crítica nos impactos ambientais dos produtos de construção civil. No caso das argamassas, como a maior parte da massa da argamassa é constituída pelo agregado miúdo, seu transporte se torna crítico e foi verificado no presente estudo, principalmente para o cenário mais pessimista, em que se considerou que a areia é transportada de uma distância de $200 \mathrm{~km}$. É comum que a localização de pedreiras e jazidas de areia sejam mais próximas que fábricas de cimento, no entanto, com a evolução do consumo, essas reservas podem se esgotar, e em alguns casos esse cenário já é realidade. Nessa perspectiva, é necessário utilizar areia de locais mais distantes, o que pode aumentar os impactos ambientais do transporte. Uma alternativa frequentemente empregada no setor da construção civil em caso de locais muito distantes para a obtenção de areia natural é optar por areia britada, que também pode ter repercussão na dosagem da argamassa devido às características mineralógicas e ao formato diferente da partícula dos dois agregados. Santoro e Kripka (2016) verificaram distâncias de $5 \mathrm{~km}$ para areia britada e de $274 \mathrm{~km}$ para a areia natural, corroborando esse possível cenário. 
Uma alternativa que já vem sendo aplicada em algumas obras é o uso de agregados reciclados (resíduos Classe A) para confecção de argamassas. Do ponto de vista ambiental, especificamente pensando no transporte, a alternativa mais vantajosa seria a reciclagem e uso desses agregados no próprio canteiro, o que já é adotado em algumas empresas. Por outro lado, como apontam Caldas e Sposto (2017), especialmente se forem requeridos produtos oriundos de fábricas classificadas nos Programas Setoriais da Qualidade (PSQ), o que é bastante aconselhável, o que vale especialmente para o cimento Portland, os impactos de transporte podem aumentar consideravelmente. Nesse sentido, é recomendado que essa análise seja realizada avaliando-se a disponibilidade dos insumos e o impacto no desempenho e na qualidade da argamassa produzida. Como neste estudo foram avaliados cenários extremos para a etapa de transporte, era de se esperar que a incerteza relativa aumentasse para as categorias de impacto em que a queima de diesel é significativa (GWP100, ODP, AP, EP e ADP-ff). No entanto, em casos reais é comum que certos materiais estejam mais próximos e outros mais distantes. Como o transporte é influenciado pela massa transportada, a areia é o insumo que tende a mais impactar os resultados finais, principalmente em cenários de escassez desse recurso.

Quando as perdas são quantificadas em formas de impactos ambientais, é possível verificar que contribuem pouco em relação às outras etapas e parâmetros avaliados. Mesmo assim, é importante que elas sejam avaliadas e minimizadas, pois podem impactar em pontos que não foram avaliados no presente estudo, como organização do canteiro e interferência na logística de operação.

Para finalizar, embora não tenha sido objeto de pesquisa deste estudo, é fundamental que os projetistas e construtores não se esqueçam das boas práticas de um projeto de revestimento argamassado. Entre elas podem ser citadas:

(a) especificação dos materiais constituintes, definição das espessuras mínima e máxima de cada camada (de acordo com o desempenho desejado e local de aplicação);

(b) instalação de reforços caso sejam necessários; e

(c) definição das juntas de movimentações e correta execução (limpeza do substrato, cura, intervalo entre as camadas, etc.).

Todos esses cuidados contribuirão para uma maior durabilidade e vida útil do revestimento argamassado, e, consequentemente, menor necessidade de manutenções ou reposições do revestimento (que representou ser responsável por aproximadamente a metade dos impactos ambientais no ciclo de vida do revestimento).

\section{Conclusões}

$\mathrm{O}$ uso da ACV permitiu calcular potenciais impactos ambientais de diferentes combinações de composições de chapisco e camada única normalmente empregadas no setor da construção civil brasileira. Foi possível traçar algumas estratégias para a mitigação dos impactos ambientais de revestimentos argamassados no Brasil.

O cimento e a cal hidratada foram os insumos mais impactantes. As combinações chapisco com traço 1:3 e camada única de 1:1:6 e de 1:2:8 foram as mais impactantes para a maioria das categorias de impacto avaliadas, enquanto a combinação chapisco 1:5 e camada única 1:3:12, a menos impactante. A carbonatação da argamassa pode ter um impacto significativo, chegando a $16 \%$, na redução potencial do aquecimento global. Para o chapisco rolado, o uso de adesivo butadieno pode aumentar consideravelmente alguns impactos, como o potencial de aquecimento global e a depleção de combustíveis fósseis.

O tipo de processo executivo teve grande influência na maioria dos impactos ambientais avaliados devido aos diferentes consumos de materiais para cada tipo de processo. As técnicas combinadas de chapisco rolado e camada única projetada se mostraram as mais eficientes, com ganhos de até $64 \%$ em relação às técnicas de execução convencional.

Em futuros estudos, deve ser explorado como essas diferentes combinações de argamassa, em termos de propriedades, influenciam questões de desempenho e durabilidade dos revestimentos. É importante que seja realizada uma pesquisa com foco na etapa de manutenção e reposição dos revestimentos, que pode ser conduzida com a avaliação de diferentes cenários e valores de VUP. Sugere-se também a avaliação de outros tipos de argamassas presentes no mercado, como as industrializadas e as estabilizadas. Uma nova modelagem considerando dados mais representativos dos insumos da argamassa, principalmente o cimento e a areia, para o contexto brasileiro deve ser realizada. 


\section{Referências}

ALBUQUERQUE, H. R.; LIRA, J.; SPOSTO, R. M. Emissões de $\mathrm{CO}_{2}$ de sistemas de revestimento de argamassa: estudo de caso de aplicação de argamassa projetada comparativamente à aplicação convencional. Ambiente Construído, Porto Alegre, v. 18, n. 4, p. 377-393, out./dez. 2018.

ANAND, C. K.; AMOR, B. Recent developments, future challenges and new research directions in LCA of buildings: a critical review. Renewable and Sustainable Energy Reviews, v. 67, n. 1, p. 408-416, jan. 2017.

ASSOCIAÇÃO BRASILEIRA DE NORMAS TÉCNICAS. NBR 15220-2: desempenho térmico de edificações:parte 2: método de cálculo da transmitância térmica, da capacidade térmica, do atraso térmico e do fator solar de elementos e componentes de edificações. Rio de Janeiro, 2005.

ASSOCIAÇÃO BRASILEIRA DE NORMAS TÉCNICAS. NBR 15575: edificações habitacionais: desempenho. Rio de Janeiro, 2013.

ASSOCIAÇÃO BRASILEIRA DE NORMAS TÉCNICAS. NBR ISO 14040: gestão ambiental: avaliação do ciclo de vida: princípios e estrutura. Rio de Janeiro, 2009.

BORGES, P. H. R. et al. Estudo comparativo da análise de ciclo de vida de concretos geopoliméricos e de concretos à base de cimento Portland composto (CP II). Ambiente Construído, Porto Alegre, v. 14, n. 2, p. 153-168, abr./jun. 2014.

BRÁS, A.; FARIA, P. Effectiveness of mortars composition on the embodied carbon long-term impact. Energy and Buildings, v. 154, p. 523-528, nov. 2017.

BRÁS, A.; GOMES, V. LCA implementation in the selection of thermal enhanced mortars for energetic rehabilitation of school buildings. Energy and Buildings, v. 92, p. 1-9, 2015.

BRASIL. Demanda futura por moradias: demografia, habitação e mercado. Rio de Janeiro: UFF, 2018.

CALDAS, L. R. et al. Avaliação ambiental de revestimentos de terra: análise da influência da vida útil no ciclo de vida. In: SIMPÓSIO NACIONAL DE TECNOLOGIA DAS ARGAMASSAS, 13., Goiânia, 2019. Anais [...] Porto Alegre: ANTAC, 2019.

CALDAS, L. R. et al. Emprego do Sinapi para quantificação de emissões de CO2: estudo de caso para o chapisco em uma habitação unifamiliar. In: ENCONTRO NACIONAL DE TECNOLOGIA DO AMBIENTE CONSTRUÍDO, 16., São Paulo, 2016. Anais [...] Porto Alegre: ANTAC, 2016.

CALDAS, L. R.; LIRA, J. S. M. M.; SPOSTO, R. M. Avaliação do Ciclo de Vida de habitações de alvenaria estrutural de blocos cerâmicos e painéis pré-moldados de concreto considerando diferentes zonas bioclimáticas. Revista Latino-Americana em Avaliação do Ciclo de Vida, Brasília, v.1, n.1, p. 138-167, 2017.

CALDAS, L. R.; SPOSTO, R. M. Emissões de $\mathrm{CO}_{2}$ referentes ao transporte de materiais de construção no Brasil: estudo comparativo entre blocos estruturais cerâmicos e de concreto. Ambiente Construído, Porto Alegre, v. 17, n. 4, p. 91-108, out./dez. 2017.

CALDAS, L. R.; TOLEDO FILHO, R. D. Avaliação do Ciclo de Vida de materiais cimentícios utilizados no Brasil: estudo para argamassas, graute e bloco de concreto. Revista Latino-Americana em Avaliação do Ciclo de Vida, Brasília, v. 2, n. 2, p. 34-61, jul./dez. 2018.

CARASEK, H. Argamassas. In: ISAIA, G.C. (org.). Materiais de construção civil e princípios de ciência e engenharia de materiais. São Paulo: Ibracon, 2010.

CIRILO, F.; MELO, A. T. S. Comparativo de desempenho ambiental entre argamassa industrializada e argamassa virada em obra. In: CONGRESSO BRASILEIRO SOBRE GESTÃO DO CICLO DE VIDA, 6. Brasília, 2018. Anais [...] Brasília: IBICT, 2018.

COLLINS, F. Inclusion of carbonation during the life cycle of built and recycled concrete: influence on their carbon footprint. The International Journal of Life Cycle Assessment, v. 15, n. 6, p. 549-556, 2010.

CONDEIXA, K.; HADDAD, A.; BOER, D. Life cycle impact assessment of masonry system as inner walls: a case study in Brazil. Construction and Building Materials, v. 70, p. 141-147, 2014. 
DE PAULA, R. R. et al. Avaliação do ciclo de vida de argamassas com resíduos de cerâmica vermelha considerando um indicador de desempenho mecânico durabilidade. In: CONGRESSO BRASILEIRO SOBRE GESTÃO DO CICLO DE VIDA, 6., Brasília, 2018. Anais [...] Brasília: IBICT, 2018.

ESCAMILLA, E.et al. Industrial or traditional bamboo construction? Comparative Life Cycle (LCA) of Bamboo-Based Buildings. Sustainability, v. 10, p. 1-14, 2018.

EUROPEAN COMMITTEE FOR STANDARDIZATION.EN 15804: sustainability of construction works: environmental product declarations: core rules for the product category of construction products. Brussels, 2012.

EVANGELISTA, P. P. A. et al. Environmental performance analysis of residential buildings in Brazil using life cycle assessment (LCA). Construction and Building Materials, v. 169, p. 748-761, 2018.

FUNDAÇÃO JOÃO PINHEIRO. Déficit habitacional no Brasil | 2013-2014. Belo Horizonte, 2016.

GAMA JUNIOR, A. C. A. Diretrizes com base em avaliação do ciclo de vida para redução de emissão de dióxido de carbono em revestimento de argamassa. Goiânia, 2013. Dissertação (Mestrado em Engenharia Civil) - Escola de Engenharia, Universidade Federal de Goiás, Goiânia, 2013.

GARRIDO, R.; SILVESTRE, J. D.; FLORES-COLEN, I. Economic and Energy Life Cycle Assessment of aerogel-based thermal renders. Journal of Cleaner Production, v. 151, p. 537-545, 2017.

GELOWITZ, M. D. C.; MCARTHUR, J. J. Comparison of type III environmental product declarations for construction products: material sourcing and harmonization evaluation. Journal of Cleaner Production, v. 157, n. 20, p. 125-133, jan. 2017.

INTERNATIONAL EPD SYSTEM. [Site official]. Disponível em: https://www.environdec.com/. Acesso em: 21 jan. 2018.

INTERNATIONAL EPD SYSTEM. Cement. Environdec [site]. EPD Votorantim Cimentos, 2017. Disponível em: http://bit.ly/2IW91IL. Acesso em: 21 jan. 2018.

LAGERBLAD, B. Carbon dioxide uptake during concrete life cycle: state of the art.Oslo: Nordic Innovation Centre, 2005.

MARTINS, A. P. S. et al. Avaliação do ciclo de vida de compósitos solo-cimento-fibras de sisal considerando diferentes distâncias de transporte. In: CONGRESSO DE ARQUITETURA E CONSTRUÇÃO COM TERRA NO BRASIL, 7., Rio de Janeiro, 2018. Anais [...] Rio de Janeiro, 2018.

MEDEIROS, L. M.; DURANTE, L. C.; CALLEJAS, I. J. A. Contribuição para a avaliação de ciclo de vida na quantificação de impactos ambientais de sistemas construtivos. Ambiente Construído, Porto Alegre, v. 18, n. 2, p. 365-385, abr./jun. 2018.

MEHTA, K.; MONTEIRO, P.Concreto: microestrutura, propriedades e materiais.São Paulo: Ibracon, 2014.

MELIÀ, P. et al. Environmental impacts of natural and conventional building materials: a case study on earth plasters. Journal of Cleaner Production, v. 80, p. 179-186, 2014.

PASSUELLO, A. C. B. et al. Aplicação da Avaliação do Ciclo de Vida na análise de impactos ambientais de materiais de construção inovadores: estudo de caso da pegada de carbono de clínqueres alternativos.

Ambiente Construído, Porto Alegre, v. 14, n. 4, p. 7-20, out./dez. 2014.

PEDREÑO-ROJAS, M. A. et al. Influence of the heating process on the use of gypsum wastes in plasters: Mechanical, thermal and environmental analysis. Journal of Cleaner Production, v. 215, p. 444-457, 2019.

PINEDA, P.; GARCÍA-MARTÍNEZ, A.; DIEGOCASTIZO-MORALES, D. Environmental and structural analysis of cement-based vs. natural material-based grouting mortars. Results from the assessment of strengthening works. Construction and Building Materials, v. 138, p. 528-547, 2017.

PITTAU, F.et al. Fast-growing bio-based materials as an opportunity for storing carbon in exterior walls.Building and Environment, v. 129, n. 1, p. 117-129, 2018.

ROMANO, R. C. de O.; CINCOTTO, M. A.; PILEGGI, R. G. Incorporação de ar em materiais cimentícios: uma nova abordagem para o desenvolvimento de argamassas de revestimento. Ambiente Construído, Porto Alegre, v. 18, n. 2, p. 289-308, abr./jun. 2018. 
SANTORO, J. F.; KRIPKA, M. Determinação das emissões de dióxido de carbono das matérias-primas do concreto produzido na região norte do Rio Grande do Sul. Ambiente Construído, Porto Alegre, v. 16, n. 2, p. 35-49, abr./jun. 2016.

SILVA, L. C. Avaliação de ciclo de vida de concretos com substituição parcial de cimento por cinzas do bagaço de cana-de-açúcar e da casca de arroz. Rio de Janeiro, 2015. Dissertação (Mestrado em Engenharia Civil) - Instituto Alberto Luiz Coimbra de Pós-Graduação e Pesquisa de Engenharia, Universidade Federal do Rio de Janeiro, Rio de Janeiro, 2015.

SILVA, M. G. da; GOMES, V.; SAADE, M. R. M. The contribution of life-cycle assessment to environmentally preferable concrete mix selection for breakwater applications.Ambiente Construído, Porto Alegre, v. 18, n. 2, p. 413-429, abr./jun. 2018.

SISTEMA de Estimativas de Emissões e Remoções de Gases de Efeito Estufa.[Plataforma online]. Disponível em: http://plataforma.seeg.eco.br/total_emission. Acesso em: 23 jun. 2019.

SISTEMA NACIONAL DE PESQUISA DE CUSTOS E ÍNDICES DA CONSTRUÇÃO CIVIL. Cadernos técnicos de composições para argamassas e grautes. Lote 1, Caixa Econômica Federal, 2017.

SOUZA, D. M. et al. Comparative life cycle assessment of ceramic brick, concrete brick and cast-in-place reinforced concrete exterior walls. Journal of Cleaner Production, v. 137, p. 70-82, 2016.

TEIXEIRA, E. R. et al. Quality and durability properties and life-cycle assessment of high volume biomass fly ash mortar. Construction and Building Materials, v. 197, p. 195-207, 2019.

UNITED NATIONS ENVIROMENT et al. Eco-efficient cements: potential economically viable solutions for a low- $\mathrm{CO}_{2}$ cement-based materials industry. Cement and Concrete Research, v. 114, p. 2-26, 2018.

UNITED NATIONS ENVIRONMENT AND INTERNATIONAL ENERGY AGENCY.Towards a zeroemission, efficient, and resilient buildings and construction sector. Global Status Report 2017.

YAZIGI, W. A técnica de edificar. 15. ed. São Paulo: Pini, 2016.

\author{
Lucas Rosse Caldas \\ Programa de Engenharia Civil |Universidade Federal do Rio de Janeiro | Cidade Universitária, CT, Bloco B, Ilha do Fundão | Rio de \\ Janeiro - RJ - Brasil | Caixa Postal 68506 | CEP 21945-970 | Tel.: (21) 2562-8479 | E-mail: Irc@coc.ufrj.br \\ Michele Tereza Marques Carvalho \\ Departamento de Engenharia Civil e Ambiental | Universidade de Brasília | Campus Darcy Ribeiro, Asa Norte, Brasília - DF - Brasil | CEP \\ 70910-900 | Tel.: (61) 3107-1010 | E-mail: micheletereza@gmail.com \\ Romildo Dias Toledo Filho \\ Programa de Engenharia Civil | Universidade Federal do Rio de Janeiro | E-mail: toledo@coc.ufrj.br
}

\author{
Ambiente Construído \\ Revista da Associação Nacional de Tecnologia do Ambiente Construído \\ Av. Osvaldo Aranha, $99-3^{\circ}$ andar, Centro \\ Porto Alegre - RS - Brasil \\ CEP $90035-190$ \\ Telefone: +55 (51) 3308-4084 \\ Fax: +55 (51) 3308-4054 \\ www.seer.ufrgs.br/ambienteconstruido \\ E-mail: ambienteconstruido@ufrgs.br
}

